\title{
Interférences
}

Ars scribendi

9 | 2016

Varia

\section{Virgile, la mémoire et les Muses : l'innovation derrière la tradition}

\section{Emmanuelle Raymond-Dufouleur}

\section{(2) OpenEdition \\ 1 Journals}

\section{Édition électronique}

URL : http://journals.openedition.org/interferences/5733

DOI : 10.4000/interferences.5733

ISSN : $1777-5485$

Éditeur

HiSoMA - Histoire et sources des Mondes antiques

Référence électronique

Emmanuelle Raymond-Dufouleur, "Virgile, la mémoire et les Muses : I'innovation derrière la tradition », Interférences [En ligne], 9 | 2016, mis en ligne le 18 janvier 2018, consulté le 10 décembre 2020. URL: http://journals.openedition.org/interferences/5733; DOI : https://doi.org/10.4000/interferences.5733

Ce document a été généré automatiquement le 10 décembre 2020.

Tous droits réservés 


\title{
Virgile, la mémoire et les Muses : l'innovation derrière la tradition
}

\author{
Emmanuelle Raymond-Dufouleur
}

1 Qu'il soit représenté entouré de Clio et Melpomène sur la célèbre mosaïque de Sousse, de Clio et Calliope sur le frontispice de l'édition de 1619 des six premiers livres de l' Énéide par J. L. de La Cerda ${ }^{1}$, ou de Calliope seule dans une édition strasbourgeoise de ses œuvres complètes datée de 1502 et illustrée par Sébastien Brant ${ }^{2}$, Virgile apparaît régulièrement accompagné de figures féminines qui renvoient, dans l'imaginaire collectif, aux divinités associées avec la création poétique.

2 Ce parti pris iconographique n'est sans doute pas étranger à la présence récurrente des Muses dans la poésie virgilienne, en particulier dans l'Énéide. À six occasions dans son épopée, Virgile convoque une ou plusieurs Muses dont il appelle l'aide mémorielle de ses vœux. Tantôt Muse familière aux traits indéterminés $(1,8)$, tantôt Muse bien précise associée par ailleurs à tel ou tel genre poétique (comme en 7, 37-41 avec le proème à Érato, ou en 9, 525-529 avec la prière à Calliope), tantôt Muses convoquées toutes ensemble (comme les déesses de l'Hélicon de 7, 641 repris en 10, 163, ou les Mousae de 9, 77), le poète alterne les possibilités de patronage, comme s'il s'octroyait lui-même le privilège d'être leur protégé à toutes, sans jamais perdre de vue le soutien mnémonique des divinités invoquées.

3 Ce brouillage des pistes appelle une enquête sur l'identité de ces figures de l'énonciation poétique, sur leur rôle dans l'Énéide et sur le pouvoir particulier que leur confère le poète. Car en comparant les occurrences antérieures et la pratique virgilienne, il apparaît que derrière la tradition se cache un pan entier du projet virgilien, à savoir l'élaboration d'un monimentum littéraire destiné à rendre " memores ${ }^{3}$ " les lecteurs contemporains et à venir. 


\section{Musa mihi causas memora : entre inspiration poétique et mémoire}

4 L'ouverture de l'épopée virgilienne ${ }^{4}$ sur la requête du poète à la Muse de le faire se souvenir des raisons pour lesquelles Junon poursuit Énée de sa haine plonge d'emblée le lecteur dans l'univers de l'inspiration poétique et de ses représentantes (1, 8-11):

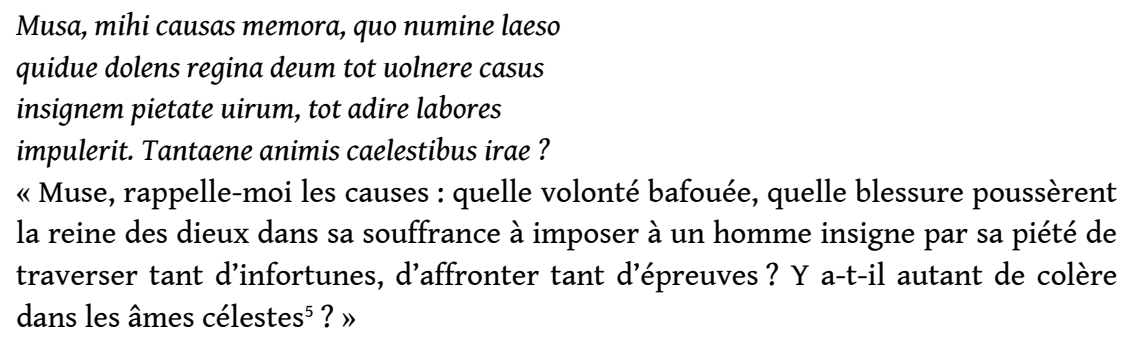

Malgré une association qui nous parait aujourd'hui des plus naturelles, ce lien entre les Muses et la mémoire est loin d'aller de soi à Rome. Contrairement au modèle grec qui établit un lien de filiation entre les Muses et Mnémosyne, les Muses à Rome, en tout cas à l'époque classique, ne sont pas directement associées à la mémoire. Ce lien novateur établi par Virgile mérite donc toute notre attention, ne serait-ce que pour tenter d'éclaircir une première question : Virgile est-il si imprégné de littérature grecque qu'il a simplement imité la tradition grecque associant les Muses à la mémoire, ou cette association est-elle le tout premier signe d'un profond intérêt virgilien pour le rôle de la mémoire dans sa propre poétique?

\section{Memoria ou Mnémosyne : le duel}

La fonction spécifique que le poète confère à la Muse anonyme de l'Énéide 1,8 , personnage encore énigmatique à ce stade, spécialement sollicité pour « faire surgir les souvenirs ", permet de lancer une première hypothèse de travail : l'indétermination de l'identité de cette Muse constituerait une trace visible de l'absence à Rome d'une déesse Memoria.

7 En effet, l'interpellation générique opérée par Virgile répond à l'absence d'une déesse Memoria dans le panthéon des abstractions érigées au rang de divinités par les Romains $\mathrm{du} \mathrm{I}^{\mathrm{er}}$ siècle av. J.-C. La pratique romaine qui consistait à transformer certains concepts comme la fides, la «loyauté», ou bien la concordia, l'«harmonie civile», en divinités susceptibles d'être matérialisées et représentées sur des supports divers comme les pièces de monnaie ou les sculptures d'édifices religieux a fait florès dans l'Antiquité romaine, qui s'est inspirée en cela de nombreux précédents grecs ${ }^{6}$. L'exemple romain sans doute le plus célèbre de ce phénomène est la divinisation de la fortune ${ }^{7}$, opérée par Sylla sous le nom de Felicitas, puis, à sa suite, de façon plus saisissante encore par Pompée sous le nom de Fortuna.

8 Il ne nous est parvenu qu'un seul fragment latin, extrait vraisemblablement d'une pièce de Lucius Afranius (Com. 298, éd. RIBBECK, 1898) et repris par Aulu-Gelle, qui évoque de façon extrêmement brève une certaine Memoria $(13,8,3)$ :

Vsus me genuit, mater peperit Memoria

Sophiam uocant me Grai, uos Sapientiam...

«Usage m'a donné la vie, ma mère Mémoire m'a donné le jour, les Grecs

m'appellent Sophia et vous m'appelez Sagesse ». 
s'agit-il d'un personnage inventé par Afranius ou d'une forme d'hapax legomenon - ce qui légitimerait sa reprise et sa conservation par le compilateur Aulu-Gelle ? L'absence de contexte et l'indétermination de ces éléments nous interdisent toutefois de tirer des conclusions valables de cet extrait. En revanche, dans certaines sources tardives, il semblerait que la déesse Memoria ait remplacé la déesse grecque Mnémosyne. Ainsi Isidore de Séville rapporte dans ses Étymologies, sans doute en citant saint Augustin (De ordine 2,14, 41), que les Muses étaient filles de Memoria (Orig. 3, 15, 2):

Inde a poetis Iovis et Memoriae filias Musas esse confictum est.

«C'est de là que les poètes ont imaginé que les Muses sont filles de Jupiter et de

Memoria. »

10 Une déesse Memoria figure également chez Arnobe (Aduersus nationes 2, 70, 3), sans doute comme une référence à la déesse de la mémoire et là encore en remplacement de Mnémosyne, puisqu'elle apparaît dans une longue liste de divinités olympiennes ; dans un second passage (Aduersus nationes 3, 37,1), elle est présentée comme l'épouse de Jupiter et la mère des Muses, parfois confondue avec une déesse Mens (Iovis ceteri praedicant ex Memoria uxore vel Mente, "tous les autres disent qu'elle est la fille de Memoria l'épouse de Jupiter ou de Mens »).

11 Ces attestations sont toutefois marginales et tardives, et ne permettent pas de plaider l'existence d'une déesse de la mémoire à l'époque classique.

12 Pourtant, Virgile aurait pu, sans grande difficulté, proposer une personnification de la notion de mémoire ${ }^{8}$. La liberté du poète autorise assez fréquemment à inventer ou à créer certaines formes hybrides ou néologismes et à introduire toutes sortes d'innovations. Et les précédents en la matière sont légion. Ainsi, les épopées grecques antérieures offrent un large spectre d'abstractions personnifiées: on trouve chez

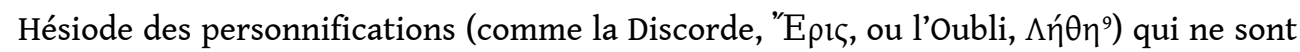
pas de réels personnages du récit dans la mesure où elles n'ont pas autant $d^{\prime}$ '« épaisseur » que d'autres divinités bien répertoriées (comme les dieux olympiens) et n'ont pas d'influence sur le destin des humains; elles représentent certaines émotions ou encore des manifestations de l'affect humain.

Plus complet est le tableau offert par l'épopée homérique qui présente des personnifications réduites à l'état de divinités de second rang, à l'image des compagnes d'Arès : Deimos (la Panique), Phobos (la Crainte) et Éris (la Discorde), qui constituent son cortège guerrier $(I l .4,440$ et 15,119). Le rôle d'Éris paraît déjà quelque peu supérieur à celui des deux autres personnifications, probablement parce que le poète donne une description mimétique de son action sur les hommes ${ }^{10}$; mais il n'atteint pas toutefois l'importance accordée à Hypnos (le Sommeil) et à Thanatos (la Mort), qui semblent intervenir directement dans le récit et la destinée humaine, notamment au moment où les deux divinités emportent le corps sans vie de Sarpédon (Il. 16, 681-683).

14 Grâce à la réorganisation des fragments conservés des poèmes du cycle épique, les épopées post-homériques apportent une confirmation (relative, étant donné l'état fragmentaire du corpus) sur le rôle croissant octroyé aux personnifications dans les œuvres antérieures à l'Énéide :

La technique de l'utilisation de personnifications comme acteurs majeurs de l'épopée semble avoir été utilisée très tôt. Les Chants Cypriens sont le lieu, apparemment, d'un usage intensif des personnifications. On entend parler de Thémis (la Justice), d'Éris (la Discorde), de Némésis (la Vengeance) et peut-être aussi 
de Momus comme de personnages et l'on reconstruit le passage où la Discorde dissémine son essence parmi les invités du mariage de Thétis et Pélée, mais la nature fragmentaire de cette preuve nous interdit de savoir de quel genre d'énergie ou de personnalité la Discorde et ses homologues étaient gratifiés ${ }^{11}$.

Mnémosyne qui a suscité la confusion chez les auteurs antiques précédemment cités. L'hypothèse est intéressante car soutenue par l'allitération en /m/ du v. 8 (Musa mihi

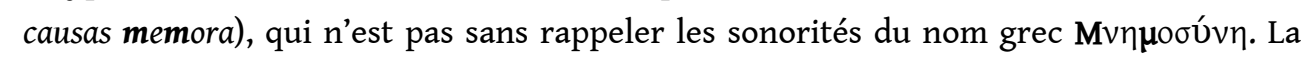
tradition poétique la présente comme une Titanide, la sœur de Cronos et d'Océanos et la mère des neufs Muses, avec lesquelles elle est parfois confondue. Dans la Théogonie d'Hésiode ${ }^{13}$, elle apparaît comme une divinité omnisciente à l'origine du souffle divin qui préside à l'activité poétique et permet au poète, alors possédé par

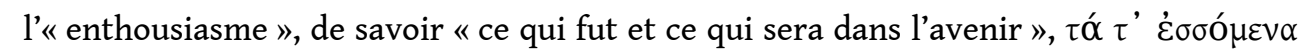

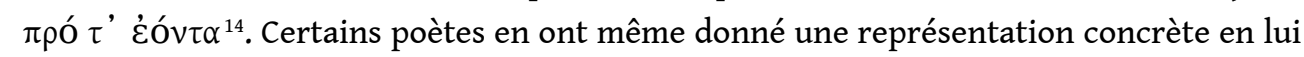
octroyant des qualités physiques ou des propriétés visuelles comme une belle chevelure ${ }^{15}$ ou encore un péplos doré16.

La déesse Mnémosyne, qui n'apparaît tout au plus qu'une douzaine de fois dans la littérature grecque, semble en effet avoir obtenu ses lettres de noblesse dans une période où la littérature orale - et les formes qui lui sont assimilables - florissait, la Grèce archaïque des $\mathrm{VII}^{\mathrm{e}}$ et $\mathrm{vl}^{\mathrm{e}}$ siècles av. J.-C. Un passage de l'Hymne à Hermès (daté de la fin $\mathrm{du} \mathrm{VI}^{\mathrm{e}} \mathrm{s}$.), dans lequel le dieu Apollon rend un hommage appuyé à la déesse Mnémosyne, la marraine du dieu Hermès, apparaît comme une confirmation évidente de ce trait de la poésie archaïque (v. 429-430) :

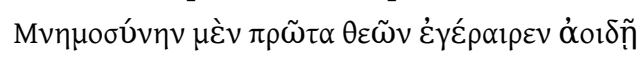

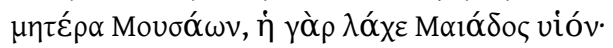

«C'est Mnémosyne, la première entre les dieux, qu'il glorifia par son chant, la mère

des Muses, la divinité qui fut donnée comme patronne au fils de Maïa... »

18 Il est difficile de dire si le chant de Phébus constitue ou non l'acte de naissance d'un culte de Mnémosyne en Grèce mais, de toute évidence, il apparaît comme un indice de cette croyance qui sera confirmée plus tard par une scholie alexandrine portant sur l' ๔edipe à Colone de Sophocle, où l'exégète profite d'une allusion au culte des Érinyes pour évoquer le culte rendu à Mnémosyne - entre autres - à Athènes (Schol. In Oedipum Colonum 100, 4 - 100, 6) :

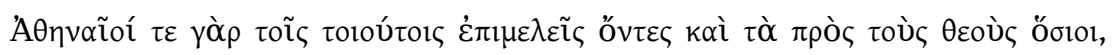

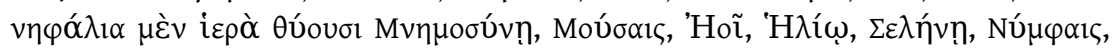

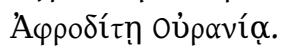

«En effet, les Athéniens s'occupaient des choses religieuses avec grand soin et étaient très pieux à l'égard des dieux, c'est pour cela qu'ils offraient des libations sans vin à Mnémosyne, aux Muses, à Éos, à Hélios, à Sélénè, aux Nymphes et à Aphrodite Ouranienne. »

19 L'absence de référence à une temporalité particulière (il n'y a pas d'adverbe du type

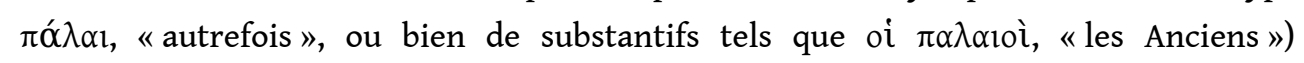
empêche de situer le culte en question dans une chronologie précise. S'agissant non plus du domaine religieux à proprement parler mais du domaine littéraire, J. Notopoulos évoque l'influence de la déesse de la mémoire et sa prise en considération 
dans des œuvres dont la caractéristique principale est de se situer à la frontière entre écriture et oralité. À mesure que la littérature grecque s'est acheminée vers des formes plus écrites que récitées (à l'image de la poésie aédique), la prépondérance (littéraire ou mythologique) de Mnémosyne dans les textes s'est considérablement amoindrie en sorte que, de véritable inspiratrice de la production poétique, elle est devenue une simple divinité tutélaire pour le poète :

Avec le changement de méthode de composition allant d'un style oral et naturel vers une composition écrite, Mnémosyne perdit sa fonction. La littérature écrite préserva son existence dans une théologie reçue en héritage; les poètes qui étaient alors au seuil de cette période de transition continuèrent à commencer leur chant poétique par une invocation à Mnémosyne comme jadis l'aède le faisait, mais à partir de là ce fut une pure convention littéraire ${ }^{17}$.

Le sentiment de cette déperdition dans le statut d'autorité de Mnémosyne est d'ailleurs lisible dans l'Héraclès d'Euripide où le chœur se fait sans doute l'écho du poète lorsqu'il dit (v. 678-679) :

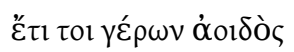

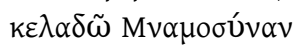

«même vieux, moi le poète, je chante Mnémosyne ».

Ce rappel de l'obligation poétique d'honorer la déesse de la mémoire résonne quelque peu, en ce $\mathrm{v}^{\mathrm{e}}$ siècle, comme l'épitaphe de Mnémosyne dont le tombeau ne serait pas encore tout à fait scellé : par la parole performative du chœur, le poète tragique fait l'aveu du sacrifice qu'il concède à la célébration conventionnelle de la déesse Mnémosyne, tout en reconnaissant implicitement que, si obligation pour le poète il doit y avoir, c'est en vérité parce que Mnémosyne n'est plus considérée - dans la poésie tragique en tout cas - comme elle le devrait.

\section{Le poète et la (les) Muse(s) dans la tradition poétique pré-virgilienne}

Si ces considérations sur Memoria et Mnemosyne n'ont pas permis jusqu'ici de dégager une perspective claire sur la position de la uox poetae virgilienne, l'étude des rapports des poètes de la tradition pré-virgilienne avec les Muses et l'examen de la fonction mémorielle qu'ils leur accordent laissent entrevoir une pluralité de possibilités poétiques auxquelles Virgile s'est trouvé confronté.

La poésie homérique, en ce qu'elle est à la fois un point de départ et un point de repère de l'ensemble de la littérature grecque, donne à lire, dans ses deux versants iliadique et odysséen, une posture d'énonciation qui est adoptée ou réfutée en fonction de l'importance que chaque auteur, à la suite d'Homère, a souhaité accorder à l'héritage de

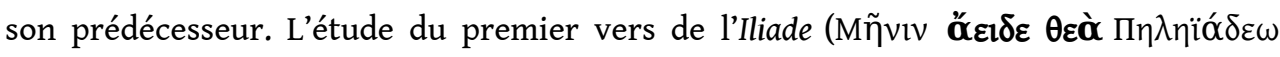

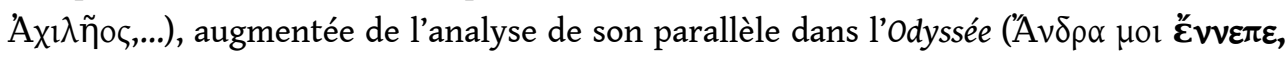

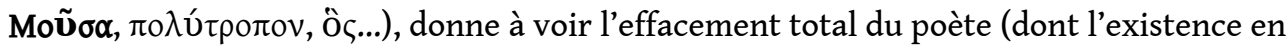
tant que figure énonciatrice est niée dans le premier cas et évoquée rapidement par un pronom à un cas oblique dans le second cas : $\mu \circ)$ ) devant la figure de la divinité

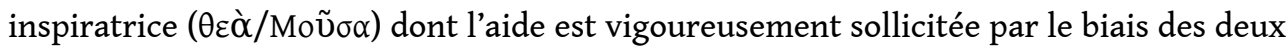

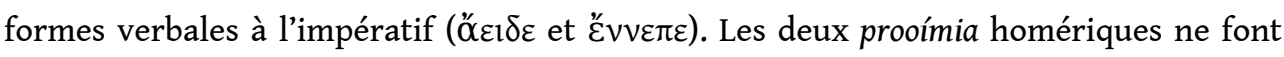
certes pas appel à l'intervention de Mnémosyne en personne mais c'est de la fonction mnémonique de la Muse que le poète se recommande au début de son œuvre épique, comme pour se concilier la faveur de celle-là seule qui saura lui fournir les capacités extraordinaires - voire quasiment divines - pour mener à bien sa performance aédique 
en se souvenant - au moment opportun et dans l'ordre - des éléments constitutifs de son chant $^{18}$. Ainsi, en opérant un changement de nom et en invoquant la déesse de la mémoire sous le nom générique de "Muse ", Homère est peut-être le premier à avoir participé au «meurtre ${ }^{19}$ » de Mnémosyne, dans la mesure où tous les poètes ultérieurs, qu'ils aient adopté une posture d'imitation fidèle ou de prise de distance affichée par rapport aux œuvres d'Homère, se réclament de la simplification et de la réduction

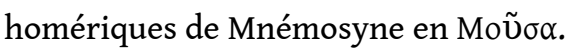

Tout en restant dans la lignée de la poésie épique homérique, l'exemple de la sphragis initiale de la Théogonie d'Hésiode propose une évolution déterminante : le premier vers

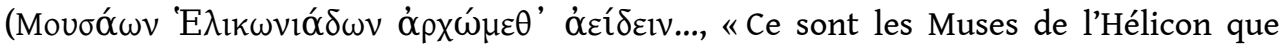
nous prenons comme origine de notre chant...») réaffirme, ne serait-ce que par la position des mots, la précellence des Muses sur le poète qui n'est présenté qu'au v. 22 et seulement en tant que dépositaire du chant que celles-ci ont bien voulu lui confier : $\alpha$ í

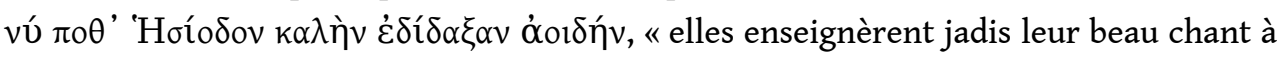
Hésiode ».

Mais une fois le prélude narratif achevé, Hésiode consolide son statut d'auteur en

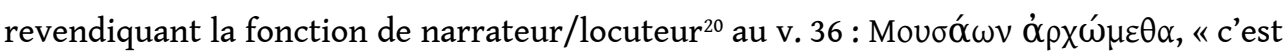
par les Muses que nous allons commencer ».

Quant au début du poème didactique Les Travaux et les Jours, il sonne comme une confirmation de l'énonciation poétique telle qu'elle est présentée dans la Théogonie. Le début des deux œuvres présente une structure analogue. À l'invocation des Muses de

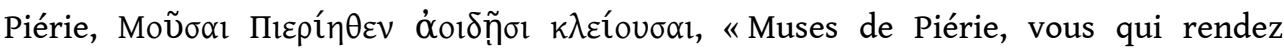
hommage par vos chants » (Op.1), succède une prise de parole du poète marquée par le

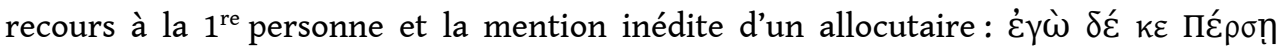
$\dot{\varepsilon} \tau \eta ́ \tau u \mu \alpha \mu \nu \theta \eta \sigma \alpha i ́ \mu \eta v, ~ «$ Moi je vais raconter à Persès des choses vraies » (Op. 10).

Alors que, dans la poésie homérique, la Muse était perçue comme la seule instance d'autorité poétique, les exemples hésiodiques dévoilent une sorte de mise en retrait de la Muse, comme si déjà avec Hésiode sa place n'était plus que dans l'invocation proémiale, à l'avant-poste d'une poétique qui cherche à s'émanciper et à s'affirmer comme indépendante :

... le je hésiodique n'est pas toujours le simple destinataire des paroles de miel des Muses; en certains passages, il assume pleinement la fonction attachée à son rôle énonciatif de narrateur. Cette situation ambiguë est significative de la position intermédiaire qu'occupe Hésiode non seulement entre une tradition orale et une poésie qui fait de plus en plus appel à l'écriture, non seulement entre un genre théogonique et un genre didactique tous deux distincts des poèmes épiques et aédiques de type homérique, mais peut-être entre une société où l'influence des dieux est ressentie comme prédominante et une vie civique dans laquelle l'individu assume une responsabilité sociale qui a pour résultat une efficacité pratique grandissante ${ }^{21}$.

Cette avancée, esquissée par Hésiode, d'une forme de délégation de la parole poétique à la Muse semble avoir été poussée plus loin encore par son continuateur, Hécatée de

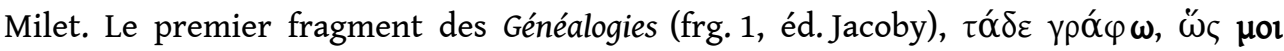

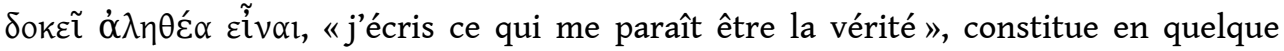
sorte une forme d'hybridation entre la conception de l'inspiration et du rôle des Muses dans la poésie homérique (avec le pronom personnel au datif $\mu o \imath$ ) et celle développée dans la poésie hésiodique (grâce à la marque de la $1^{\text {re }}$ personne, $\gamma \rho \alpha ́(\varphi \omega)$ ). Mais, et c'est en cela que l'évolution est saisissante, d'après les fragments qui nous sont parvenus 
(avec toutes les réserves que cela implique), la Muse est apparemment écartée de la liste des instances d'énonciation. Sa disparition prouverait combien, au v viècle déjà, à l'époque d'Hécatée de Milet, sa voix n'est plus considérée comme faisant autorité :

La rédaction écrite du récit généalogique, probablement envisagée en tant que produit de l'activité du suggráphein propre à des logographes tels que Thucydide, est assumée dans sa vraisemblance par le locuteur-je (anonyme) [...] L'acte d'écriture est ainsi subordonné à la parole orale argumentée et c'est le nom propre qui, en devenant son sujet, endosse le rôle que la Muse assume traditionnellement dans la poésie épique. [...] Appartenant aussi au genre généalogique, le récit d'Hécatée n'est donc plus assumé par la voix de Muses également désignées dans leur identité civile, mais par celle d'un historiographe dont la parole se fonde sur l'écriture ${ }^{22}$. l'importance de la Muse depuis Homère jusqu'à Hécatée en passant par Hésiode s'avère tendancieuse puisque aucun des trois poètes ne travaille sur le même genre poétique. C'est pourquoi, puisque c'est avec l'épopée que cette démonstration a débuté, c'est par l'épopée qu'elle doit s'achever avec le proème des Argonautiques d'Apollonios de Rhodes, qui porte un coup fatal aux Muses homériques et hésiodiques. Le poète commence en effet son chant par la mention d'Apollon qu'il cite non pas dans une invocatio mais bien dans une evocatio, en sorte que ce n'est pas tant l'Apollon protecteur des arts et des lettres qu'il sollicite ${ }^{23}$ mais l'Apollon Phoibos, dieu des oracles et prophéties dont la parole est à l'origine de l'épopée ${ }^{24}(1,1-2)$ :

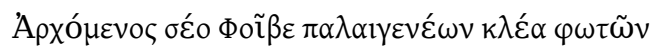

$\mu \vee \eta ́ \sigma o \mu \alpha ı$ oì....

«C'est en commençant par toi, Phoebus, que je m'apprête à chanter les hauts faits de ces mortels d'autrefois qui... »

Les deux marques de la $1^{\text {re }}$ personne (Apxó $\mu \varepsilon v o \zeta$ et $\left.\mu v \eta ́ \sigma o \mu \alpha \iota\right)$, mises en relief en début de chaque vers, correspondent à une affirmation forte par le poète de sa fonction auctoriale qui n'est plus du tout, comme chez ses prédécesseurs, remise en question et/ ou laissée - tout ou partie - aux bons soins de la Muse puisque cette dernière, dans une structure inversée par rapport au proème de la Théogonie, n'apparaît plus

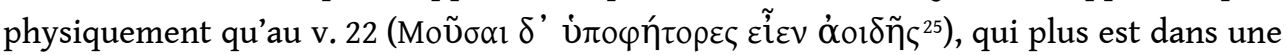
adresse indirecte empreinte d'une forme de révérence marquée par la substitution de

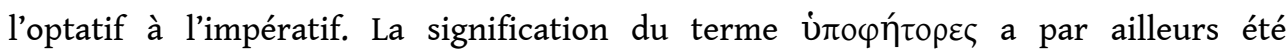
longuement débattue par les philologues ${ }^{26}$, qui ont hésité entre le sens de "qui suggère » et celui de « qui interprète ».

De fait, dans les Argonautiques le rapport du poète aux Muses s'avère particulièrement complexe, si ce n'est insaisissable, puisque, tout en tenant compte de la tradition antérieure, Apollonios propose à son lecteur certains éléments d'une modernité indéniable. C'est ainsi qu'il semble mener à son terme l'entreprise qu'Hésiode n'avait fait qu'ébaucher dans Les Travaux et les Jours en réutilisant au v. 20 du livre 1 le verbe $\mu v \theta \eta \sigma \alpha i ́ \mu \eta v$ qu'Hésiode avait choisi (v. 10) pour revendiquer la possession de la parole poétique ${ }^{27}$. Il n'y a rien d'étonnant à ce qu'un poète alexandrin comme Apollonios ait clairement affiché une posture de rupture avec la tradition antérieure, et ce, dès le proème entendu comme le lieu privilégié où chaque auteur expose le positionnement de sa propre œuvre à l'égard de la tradition générique antérieure. Si l'on part des invocations aux Muses présentes dans les Argonautiques, et au détriment de l'hypotexte homérique $\left(I l .16,235^{28}\right)$ qui donne à lire le verbe ن் donc d'« être l'interprète de $»^{29}$, on constate le rôle grandissant de la Muse dans 
l'épopée apollonienne $\mathrm{e}^{30}$ : sa quasi-absence, remarquable au livre 1 , fait place à une adresse directe à l'attention d'Érato au chant $3(3,1)$ :

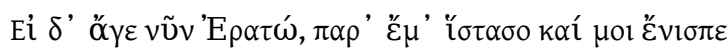

«Allons, à présent Ératô, viens t'asseoir à mes côtés et dis-moi... »

à la suite de laquelle le poète finit par abdiquer sa fonction auctoriale pour laisser le champ libre à la Muse redevenue, au début du chant 4 , une locutrice privilégiée $(4$, 1-2):

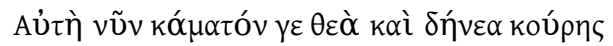

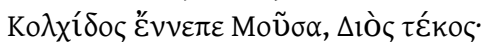

«Et maintenant, déesse, veux-tu dire toi-même les tourments et pensées de la jeune

femme de Colchide, toi la Muse, fille de Zeus?»

L'effacement du poète, rendu sensible par l'absence de marque de la $1^{\text {re }}$ personne, est

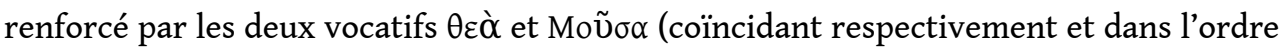
avec le v. 1 de l'Iliade et le v. 1 de l'Odyssée) pour donner l'impression paradoxale qu'Apollonios finit par céder, au livre 4 , à la tentation homérique d'une poétique inspirée par les Muses. Mais laissant de côté l'imitatio homérique, la vox poetae, dans une ultime pirouette et un sursaut d'honneur, reprend en main la responsabilité du poème épique. Pour l'écriture du poème, le poète s'était fait l'élève docile des Muses, si docile qu'il leur avait parfois laissé la voix/voie libre au point qu'après avoir en quelque sorte spolié le narrateur de ses droits elles étaient devenues autonomes, presque réelles ${ }^{31}$, et avaient pris en charge le récit épique $(4,1381)$ :

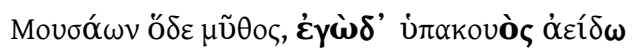

$\Pi ı \varepsilon \rho i ́ \delta \omega \nu . .$.

«Voici donc le récit des Muses; mais c'est bien moi, docile auditeur des Piérides,

qui suis l'auteur de ce chant ${ }^{32}$... »

Ce retournement final (dans le sens duquel abonde l'interprétation du préfixe ن்iòcontenu dans l'adjectif ن் dépendance des Muses vis-à-vis du poète) donne à voir un infléchissement dans la position poétique d'Apollonios qui, au fil des livres, oriente son propos vers une plus grande prise en compte de l'autorité des Muses qui seules sont capables de rendre crédible son œuvre et d'en sanctionner l'acte d'écriture et de " publication »".

Sa démarche reste donc à l'origine d'un changement majeur dans la représentation du rapport entre la Muse et le poète dans le processus de la création poétique, ne serait-ce que du point de vue de la familiarité qu'il instaure avec la Muse, à laquelle il réclame clairement de quitter les hauteurs solennelles de l'Hélicon pour venir modestement s'asseoir à ses côtés ${ }^{34}$. Car ce n'est pas tant en fonction de l'appartenance du texte à la sphère de l'oralité ou bien à celle de l'écrit qu'il convient d'envisager la mise en œuvre de la délégation puis de la relégation de la Muse, mais c'est davantage à la mise en place de jeux énonciatifs, où l'identité du je du locuteur s'affronte (par une multiplicité de masques dont la Muse fait partie) avec l'identité sociale du poète, qu'il faut vraisemblablement rattacher, sinon l'effacement, du moins l'éloignement de la Muse dans la poésie - épique ou mélique - grecque et notamment alexandrine ${ }^{35}$. Ainsi, par la mise à l'écart initiale de la Muse et son rattachement tardif à cette dernière, Apollonios inaugure une voie nouvelle qui va se situer en concurrence avec la tradition homérique et va consacrer la "sécularisation des Muses $^{36}$ ». À sa suite, les poètes devront, au seuil de leur œuvre épique, choisir l'une ou l'autre posture poétique et ainsi placer leur poème sous le patronage de l'un ou l'autre modèle. 


\section{Muses homériques ou apolloniennes?}

D'après les fragments conservés des Annales, Ennius choisit visiblement de privilégier les Muses d'Homère plutôt que celles d'Apollonios au moment d'entreprendre son récit (Ennius, Ann., frg. 1, éd. vaHLEN) :

Musae, quae pedibus magnum pulsatis Olympum

"Muses qui ont foulé de leurs pas le grand Olympe... »

Nul doute que la sauvegarde littéraire des Muses de l'épopée homérique a coïncidé avec la volonté de Fulvius Nobilior, le patron et ami d'Ennius ${ }^{37}$, qui donna aux Muses grecques un second souffle de vie, un souffle désormais vivace et italien, en introduisant des statues les représentant dans le temple d'Hercules Musarum qu'il fit construire $^{38}$. La nature fragmentaire du proème empêche toute certitude concernant l'absence, ou du moins la mise en retrait, de la voix du poète mais de toute évidence, en prenant Musae comme premier mot de son œuvre dans ce qu'on peut supposer être logiquement une prière d'invocation, c'est à la tradition homérique de l'autorité des Muses dans le processus d'inspiration poétique qu'Ennius se rattache dès l'abord. Le respect de cette tradition est d'autant plus remarquable que le terme Musa semble correspondre à une translittération du substantif homérique Moṽ $\alpha$ qui sonne comme une innovation hellénisante en rupture avec les Camènes des prédécesseurs d'Ennius ${ }^{39}$. La fin du vers, quae pedibus magnum pulsatis olympum, apporte une forme de confirmation du choix d'Ennius de privilégier les Muses d'Homère en excluant celles d'Apollonios puisque les Muses sont représentées en train de danser sur les hauteurs de l'olympe.

Ainsi, à la sécularisation opérée par Apollonios dans les Argonautiques, Ennius substitue une re-sacralisation des divinités qui ont quitté le vulgaire pour réintégrer en quelque sorte leur habitat naturel et divin ${ }^{40}$. Par ce déplacement spatial et la réhabilitation des Muses au sein du proème programmatique, le poète renoue avec la tradition de la préséance des Muses et les modalités de l'inspiration poétique telles qu'elles sont présentées dans les épopées homériques. Résonnant comme une sorte de validation métapoétique, le songe d'Ennius dans les Annales, à travers le récit de la rencontre de l'auteur avec Homère $\mathrm{e}^{41}$, rappelle l'admiration d'Ennius pour Homère tout en revendiquant, par l'intermédiaire de l'exposé de la théorie pythagoricienne de la métempsycose, sa capacité à inventer une poétique qui n'est pas tant le reflet d'une émulation féconde vis-à-vis de l'épopée homérique que la représentation de la réincarnation de celle-ci; ainsi, loin d'afficher les dehors d'un continuateur ou au mieux d'un propagateur de la poésie épique grecque, il affirme par là son essence d'inventeur, de protos eurétès, d'auctor en somme de la poésie épique latine ${ }^{42}$, statut confirmé par la réception de sa poésie au $\mathrm{I}^{\mathrm{er}}$ siècle sous la plume d'Horace qui, se voulant le porte-parole de ses contemporains, honore Ennius du titre d'alter Homerus (Ep. 1, 50-51):

Ennius et sapiens et fortis et alter Homerus

ut critici dicunt...

«Ennius, ce sage, ce vaillant, ce nouvel Homère comme disent nos critiques... »

Après Ennius, la chonologie littéraire impose bien sûr de s'intéresser au choix de Virgile et d'en venir à la question essentielle : d'Homère ou d'Apollonios, de quel poète grec le mantouan se réclame-t-il lorsqu'il invoque les Muses? Virgile choisit-il un modèle unique ou, comme nous le pensons, ses emprunts complexes sont-ils le signe 
d'une poétique nouvelle, riche de la tradition antérieure mais aussi porteuse d'un sens inédit?

39 À l'inverse de son prédécesseur immédiat ${ }^{43}$, Virgile adopte, dans les vers liminaires de $\mathrm{l}^{1}$ Énéide, une posture poétique comparable à celle d'Apollonios, puisque c'est le je du locuteur/narrateur qui ouvre l'épopée. Ainsi, que l'on choisisse de faire commencer l' Énéide par les vers proposés par la Vita Donatiana ${ }^{44}$ :

Ille ego qui quondam gracili modulatus auena

carmen et egressus siluis uicina coegi

ut quamuis auido parerent arua colono,

gratum opus agricolis, at nuns horrentia Martis...

«Moi qui jadis modulai mon chant sur un frêle pipeau et qui, sorti des bois, forçai

les campagnes alentours à obéir à un habitant plein de souhaits, œuvre agréable à

ceux qui cultivent la terre, maintenant c'est l'horreur de Mars et... »

ou que l'on privilégie l'ouverture traditionnelle, arma uirumque cano, le proème se définit par une forte présence de la figure du narrateur, alors même que, comme chez Apollonios, la Muse ne fait sa première apparition que tardivement, au v. 8, au moment où Virgile s'apprête à débuter l'exposé des causes $^{45}$ : Musa, mihi causas memora... L'ensemble de ce qui forme "l'énoncé de l'énonciation"-selon les termes de C. Calame ${ }^{46}$ - apparaît comme étant de facture apollonienne (à l'exception de la formule injonctive qui rappelle le modèle homérique) et semble donc augurer d'une poétique fondée sur une forte personnalité du locuteur-je qui laisse de côté, un instant du moins, l'autorité poétique des Muses. Et comme pour son modèle, si Virgile exclut momentanément la Muse de sa parole poétique, ce n'est que pour mieux reconnaître, au fil des chants, la dimension incontournable d'une poétique de la mémoire nécessairement liée à la présence des Muses.

40 À la lumière de l'ensemble de ces éléments, il apparaît que la relégation de la Muse n'est pas imputable au genre auquel appartient l'écrit (poétique-épique / didactiquehistoriographique) mais davantage à la place occupée par le locuteur-je et à son identification (ou non) avec la fonction auctoriale (revendiquée comme telle ou laissée à la charge des Muses). Or, à Rome au I ${ }^{\text {er }}$ siècle av. J.-C., le statut d'auteur ne va certes pas de soi: une distinction s'opère de fait entre l'auctor, c'est-à-dire l'inventeur (désigné dans les textes sous les locutions traditionnelles ille primus ou encore ego primus $^{47}$ ) ou bien l'introducteur d'un genre d'origine grecque dont il fournit une adaptation latine, et l'auteur (dans son acception moderne), c'est-à-dire toute personne qui produit un écrit destiné à être lu, récité, chanté ou représenté. Mais la coïncidence de l'identité du locuteur-je avec celle de l'auteur désigné par un patronyme recouvrant une personne physique socialement reconnue ne pose plus réellement question. Ce flou identitaire entre les instances énonciatrices, qui caractérisait la poésie épique ou mélique dans la Grèce ancienne et laissait ainsi le champ libre à un ancrage puissant de la Muse, ne constitue plus un enjeu majeur de la production littéraire à l'époque de Virgile. Il n'est donc pas étonnant que l'élite romaine de cette époque n'ait plus vu en Mnémosyne qu'une vague divinité sans consistance qui appartenait à d'anciennes pratiques poétiques grecques et, partant de là, à l'imaginaire populaire et folklorique, et dont la réactualisation n'était sans doute pas perçue comme suffisamment nécessaire pour imposer la création d'une nouvelle divinité proprement romaine.

41 À partir de ce moment-là, la fonction de masque de la Muse, derrière lequel le poète pouvait brouiller les traits de son identité, cessa d'être opératoire : «le simulacre de la Muse, par lequel le poète dissimule la manipulation sociale dont il est l'objet [...], finit 
par ne plus devenir qu'une marque générique de la haute poésie, un élément obligé de son $\operatorname{code}^{48}$ ». Mais cet effacement du rôle de la Muse dans la poésie ne justifie pas pour autant qu'on ne voie en elle qu'une "pâle métaphore ${ }^{49}$ " du processus de création poétique dont les poètes, grecs ou latins, auraient paré leurs poèmes comme pour se prémunir contre d'éventuels reproches, une convention qui devait leur permettre d'être reconnus et officialisés comme poètes œuvrant dans tel ou tel genre poétique.

La clef du problème de l'identité de la Muse virgilienne du v. 8 de l'Énéide repose en définitive sur une double imitation très claire : cédant à la tentation homérique de l'invocation à la Muse (1, 8: Musa) mais affirmant en même temps son rôle de poèteauteur (cano), Virgile oscille entre modèle homérique et modèle alexandrin ${ }^{50}$. Si ce double hommage peut donner au lecteur le sentiment d'un choix qui n'en serait pas un, l'invocation virgilienne à la Muse et le rapport du poète avec les Muses en général constituent pourtant un témoignage majeur sur le cheminement poétique de Virgile. En remplaçant la déesse de la mémoire par une attention accrue à sa fonction mnémonique, le poète introduit une troisième voie, une véritable alternative qui laisse la part belle au texte poétique lui-même. Dans cette perspective, l'absence de Memoria ou de Mnémosyne dans l'Énéide serait en réalité palliée par le texte poétique lui-même, érigé par son créateur au rang de monumentum littéraire. La Musa serait donc à la fois un hommage rendu par Virgile à ses prédécesseurs, et une façon de réinventer les codes traditionnels de l'invocation dans le genre épique en fonction de la dynamique mémorielle qui sous-tend le projet poétique ${ }^{51}$. C'est dans cette perspective qu'interviennent les « autres Muses » convoquées dans l'Énéide.

\section{Les Muses de Virgile et la définition mémorielle du projet épique}

\section{Des Muses au poète : présentation d'un transfert mémoriel}

43 À cette activité initiale de la Muse qui consiste à "mettre en mémoire », le poète en ajoute une seconde dont il ne disait rien au début de son poème : il s'agit de la capacité de la Muse (ou plus exactement des Muses) à se souvenir des choses et des événements. Lorsqu'il convoque cette fois non pas une mais des divinités mémorielles à l'appui de sa création poétique, Virgile transcende le motif topique de l'inspiration poétique en lui conférant une coloration mémorielle $(A .7,641-646)^{52}$ :

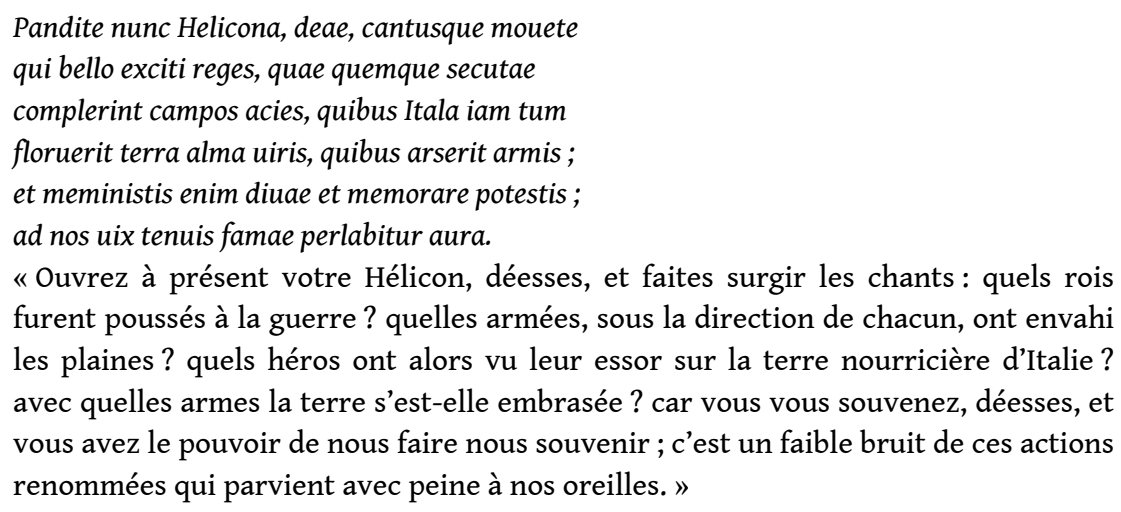

Les points de contact entre A. 1, 8-11 et A. 7, 641-646 sont multiples : en dehors de la formulation à l'impératif ( $1,8:$ memora $; 7,641$ : pandite et mouete), c'est principalement la thématique de la mémoire, déclinée dans les deux extraits, qui constitue le lien le 
plus fort (1, $8:$ memora ; 7, $645:$ meministis, memorare). Il existe cependant une différence majeure qui réside dans le passage du singulier au pluriel, qu'il s'agisse des divinités évoquées (1, $8:$ Musa, ou 7, 641 : deae, et 7, 645 : diuae), de la personne de l'allocutaire $(1,8:$ mihi) ou de celle du locuteur $(7,646:$ nos).

Le complément apporté par ce second passage est intéressant puisqu'il donne à voir le schéma de construction mémorielle complet: les Muses sont douées d'importantes capacités de remémoration (meministis) dont elles se servent pour remettre en mémoire (memorare potestis) les événements du récit dans l'esprit du poète. Le sens des verbes de l'extrait confirme cette thématique: l'impératif pandite peut en effet désigner l'ouverture d'un lieu, peut-être le Muséion ${ }^{53}$, le sanctuaire situé sur l'Hélicon dont les Muses ouvriraient les portes pour y accueillir le poète. Ce Muséion, que S. ClémentTarantino a rapproché d'un temple-bibliothèque ${ }^{54}$, offre les traits d'un lieu où seraient entreposées les archives de la mémoire des Muses, un peu comme un Tabularium ${ }^{55}$ poétique. En ouvrant les portes de leur Muséion/musée, c'est à leurs souvenirs et à leur mémoire que les Muses donnent accès au poète.

Dans son acception lucrétienne ${ }^{56}$, le verbe pandere peut aussi avoir le sens de « dévoiler » ou "mettre en lumière » un savoir caché, ce qui confirme la supériorité cognitive et mémorielle des Muses sur le poète, traditionnellement en attente d'un savoir supérieur d'origine divine dont il a besoin pour son écriture poétique.

Reste enfin une troisième acception qui est celle proposée par M. Paschalis ${ }^{57}$ et qui prend appui sur le sens de " déployer » ou « dérouler » un élément ${ }^{58}$. Le déroulement du livre de la mémoire des Muses, symbolisé par ce uolumen implicitement déployé à travers le sémantisme du verbe pandere, constitue une troisième forme de mise à disposition d'un savoir mémoriel qui demeure caché au poète de façon générale mais qui, exceptionnellement, est offert à sa connaissance par le geste d'ouverture des Muses héliconiennes.

Le verbe mouete qui clôt le vers 641 n'est pas moins digne d'intérêt. La locution cantus mouete a fait dire à P. Bing que l'extrait virgilien évoquait le passage des «Muses qui lisent » aux "Muses qui chantent $"^{59}$. Cependant, il n'est pas impossible qu'en lieu et place de ce verbe mouete ait figuré, selon une variante textuelle attestée par Servius, le verbe monete ${ }^{60}$, que Varron mettait par ailleurs sous la bannière sémantique de la mémoire ${ }^{61}$. L'hypothèse est d'autant plus séduisante qu'elle est renforcée par le passage du proème à Érato, quelques vers plus haut (7, 37-41), qui s'achève sur le vers Tu uatem, tu diua mone, dans lequel la diua Érato préfigure probablement les diuae convoquées aux vers 641 sq. Cette lecture expliciterait alors une autre transition que celle relevée par P. Bing: les Muses virgiliennes ont remplacé la lecture et le chant par l'activité de mémoire. La création poétique, anciennement requalifiée en chant (cantus), est désormais du côté d'une mémoire dispensée par les Muses. Échappant à la tradition de la figure du poète qui reçoit l'inspiration divine des Muses, Virgile redéfinit dans l' Énéide l'activité poétique comme clairement issue et produite par l'activité mémorielle dont les Muses sont à l'origine.

Cette posture du poète qui devient le réceptacle des souvenirs égrenés par les déesses de l'Hélicon ${ }^{62}$ est doublement corroborée par les vers 646 et 41 du livre 7. Il est en effet question du maigre bruit (tenuis aura) que perçoit le poète qui ne saisit qu'une infime partie des souvenirs dispensés par les Muses : ad nos uix tenuis famae perlabitur aura ( 7 , 646). Ce dernier n'occupe de surcroît la fonction de uates que parce qu'il bénéficie de l'enseignement mémoriel des Muses : Tu uatem, tu diua mone... $(7,41)$. Le topos de la voix 
du poète qui s'efface devant l'omniscience divine des Muses, largement relayé en outre par les références intertextuelles homériques, apolliniennes, enniennes ou encore lucrétiennes observables dans les extraits cités, semble renouvelé de l'intérieur par Virgile, qui subordonne l'activité poétique aux réminiscences octroyées par les déesses de l'Hélicon. Comme souvent ailleurs dans l'Énéide, la mémoire poétique ou mémoire intertextuelle du poète (ici représentée par la mémoire des Muses qui constitue une nette métaphore à valeur réflexive) est le signe d'une réflexion sur la mémoire et sur sa fonction au sein du processus de création épique ${ }^{63}$.

\section{Quelle(s) Muse(s), quelle mémoire?}

Une fois admise cette association des Muses virgiliennes avec la fonction mémorielle poétique, il convient de s'interroger sur le passage du singulier au pluriel (pourquoi la Musa de 1, 8 se transforme-t-elle en deae/diuae en 7, 641-646?) et sur les raisons profondes d'une telle mise en rapport de l'activité poétique avec les facultés mnémoniques que le poète se doit d'acquérir pour mener à bien l'exécution de son propre carmen. Lorsqu'il écrit Musa mihi causas memora $(1,8)$, le poète porte à la connaissance du lecteur un schéma d'énonciation qui met en présence la Muse qui devient, par le phénomène de l'apostrophe, l'allocutaire du propos, le poète (sous le pronom à la $1^{\text {re }}$ personne mihi) qui est le locuteur, et l'énoncé (les causes, causas) qui renvoie de façon assez évidente à un propos de type étiologique. La juxtaposition des deux termes au sein du vers ainsi que le singulier Musa permettent d'établir une plus grande familiarité dans la relation qui unit le poète et la Muse ${ }^{64}$. Si l'apostrophe à la Muse au début de l'épopée a été identifiée par les commentateurs anciens ${ }^{65}$ et

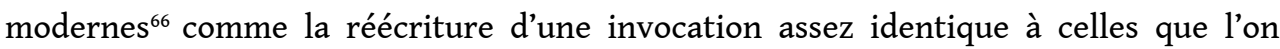
trouve chez Homère ou chez Apollonios de Rhodes, le rapport personnel entre la Muse et le poète témoigne d'enjeux poétiques supérieurs à la seule imitation littéraire.

51 Ainsi évoquée/invoquée en début de poème, la Muse assiste (à) la création poétique : elle offre son aide au poète pour la "fabrique" du récit épique et elle est présente au cœur de l'énoncé du poème, un peu comme si elle était elle-même un personnage du récit. Or, d'après le proème de l'Énéide, les souvenirs que la Muse offre au poète relient plusieurs temporalités : si la mention de Junon comme regina deum et l'évocation même du nom de Musa, dans la droite lignée des Mousai étiologiques callimachéennes (Aitia,frg. 86, 1, éd. Pfeiffer ${ }^{67}$ ), provoquent une sorte de « remontée vers le temps des origines $^{68}$ ", l'évocation d'Énée (1, 10: uirum) fait surgir la temporalité légendaire/ historique, tandis que le pronom mihi précipite au cœur de l'énonciation le temps présent de l'écriture et l'époque contemporaine du poète. Ainsi, par le détour de la mémoire, l'invocation à la Muse, qui déplace les enjeux littéraires de la stricte intertextualité jusqu'à une réflexion sur la nature de la création poétique et sur sa dette à l'égard de l'activité mémorielle, pose, dès les premiers vers de l'Énéide, un mélange des époques. Le poète présente une version de la légende d'Énée où le procédé initial de l'aition, combiné à l'invocation traditionnelle à la Muse, le tout couronné par l'idée de mémoire, mêle les aspects divins (la colère tenace de Junon) aux aspects humains (l'infortune du personnage principal), dans un jeu énonciatif où se côtoient le temps des dieux, le temps des héros et le temps du poète.

Le procédé de répétition de cette association des Muses et de la mémoire observable au livre 1 et au livre 7 tend à souligner que ce système d'énonciation est opératoire sur 
l'ensemble de l'épopée. La position proémiale occupée par les deux invocations ${ }^{69}$, à la Muse d'abord, aux déesses de l'Hélicon ensuite, augure de l'importance de l'énonciation proposée pour la lecture de l'œuvre épique comme l'héritière de la poétique homérique. Au livre 1 en effet, l'objet de la demande de commémoration de la part du poète consiste en l'exposition des raisons qui expliquent les labores d'Énée : autrement dit, le poète demande à la Muse de lui fournir des souvenirs pour la partie odysséenne de son œuvre. Quant aux vers 641-646 du livre 7, ils évoquent les rois (v. 642 : reges), les guerres (v. 642: bello) et les armes (v. 644:armis), qui rappellent que cette seconde moitié qui s'engage correspond à la partie iliadique de l'Énéide. Parce que la relation qui unit les Muses, le poète et le souvenir (tantôt souvenir des errances, tantôt souvenir des guerres) est présentée à l'orée de chacune des deux moitiés de l'épopée virgilienne, il apparaît que la mémoire est ce qui préside à la création poétique de l'ensemble de l'œuvre, définie par là-même comme le produit d'une mémoire intertextuelle certes mais aussi comme une réflexion sur la place de la mémoire dans la composition virgilienne.

53 Dans les deux extraits cités du livre 1 et du livre 7, la présence du poète sous deux formes pronominales différentes, tantôt au singulier tantôt au pluriel $(1,8:$ mihi ; , $646: n^{70}{ }^{70}$, au début et à la fin de chacune des deux formules d'inuocatio, produit l'effet d'une composition annulaire qui souligne son importance dans l'entreprise poétique. Le jeu des temps verbaux (moins perceptible avec les formulations injonctives à l'impératif) qui met en regard des subjonctifs parfait $(1,11$ : impulerit ; 7, 643 : complerint ; 7, 644 : floruerit et arserit) et des présents (7, 645 : potestis ; 7, $646:$ perlabitur $)^{71}$ relie le passé (historique et/ou légendaire) au hic et nunc de l'écriture poétique. Ainsi, le détour par l'invocation traditionnelle à la Muse offre une actualisation du récit épique qui renvoie à l'élaboration d'une poétique fondée sur une mémoire " rétroverse » (retro et uertere), à savoir sur le va-et-vient entre le temps du héros et le temps du poète ${ }^{72}$. Le passé, tel qu'il est présenté comme pratiqué par le poète à travers le prisme de l'intervention mémorielle de la Muse, n'est plus un passé absolu, tel que le définit M. Bakhtine ${ }^{73}$ et tel qu'il détermine généralement le récit épique, mais il est un passé en lien constant avec la diégèse. En se disant investi d'une parole qui n'est pas purement humaine mais bien héritière des Muses et des souvenirs qu'elles lui concèdent, le poète introduit l'idée d'un récit épique modalisé par la mémoire. Or, le discours étiologique, qui est à la source de la relation entre le poète et la Muse puisque c'est pour que surgisse le discours explicatif que ce dernier convoque les divinités de l'Hélicon, est de surcroit à l'origine du poème épique qui se veut le double développement des causes des labores d'Énée (première invocation à la Muse) et des guerres du Latium (seconde invocation aux Muses). La mémoire se trouve en quelque sorte en amont (memora / meministis / memorare potestis) et en aval (causas) du récit épique. Mais une telle observation n'explique pas pourquoi le poète convoque tantôt la Muse, tantôt les Muses, tantôt Érato et tantôt Calliope.

54 Au livre 7 en effet, avant l'invocation aux Muses de l'Hélicon, figure un premier indice de l'élaboration par Virgile d'une poétique rendue féconde par la mémoire; le proème dit "à Érato », reconnu comme la réécriture des Argonautiques $(3,1)$ d'Apollonios de Rhodes $^{74}$, propose déjà la vision d'un enseignement mémoriel (mone), dispensé par Érato, que le poète appelle à l'aide pour qu'elle lui souffle à l'oreille le déroulement des prémices des combats $(7,37-41)$ :

Nunc age, qui reges, Erato, quae tempora rerum, quis Latio antiquo fuerit status, aduena classem 
cum primum Ausoniis exercitus appulit oris

expediam et primae reuocabo exordia pugnae.

Tu uatem, tu diua mone.

«Et maintenant, allons, Érato, quels étaient les rois, les circonstances, quel était l'état de l'antique Latium lorsque, pour la première fois, une armée étrangère fit aborder sa flotte sur les rivages ausoniens ; je vais en faire le récit et je vais rappeler les origines du premier combat. Toi, déesse, toi, remémore ${ }^{75}$ au poète. »

La raison pour laquelle Virgile a convoqué Érato, la muse de la poésie lyrique et érotique $^{76}$, fait partie de ces quaestiones uergilianae qui occupent aujourd'hui encore les débats des philologues, bien que le suspense soit considérablement amoindri pour qui se satisfait de l'exégèse de Servius, lequel estime qu'Érato est mise ici pour n'importe quelle muse (Servius, A. 7, 37) :

sane Erato uel pro Calliope, uel pro qualicumque musa posuit

«il a mis Érato soit pour Calliope soit pour n'importe quelle autre muse ${ }^{77}$ ».

Même si la plupart des critiques récusent cette glose servienne comme expliquant de façon satisfaisante l'apparition d'Érato dans l'Énéide, il n'est pas si certain que Servius n'ait pas en partie compris l'enjeu d'une telle invocation, replacée dans le contexte plus vaste de l'ensemble des invocations à la / aux Muse(s) dans le poème épique. Il est vrai que le poète eût pu, comme au livre 9 , invoquer Calliope, que Lucrèce appelle sa callida Musa peut-être en vertu de ses qualités didactiques $(6,93-94)$, et dont la fonction en tant que Muse de la poésie épique eût été plus appropriée au discours que s'apprête à délivrer le poète (Lucrèce, 9, 525-528) :

Vos o Calliope precor aspirate canenti

quae ibi tum ferro strages, quae funera Turnus

ediderit, quem quisque uirum demiserit Orco

et mecum ingentes oras euoluite belli.

«Vous, ô Calliope, j'en fais la prière, donnez l'inspiration au chantre: quels massacres se déroulèrent là-bas à ce moment? de quels trépas Turnus fut-il à l'origine? quel homme dépêcha quel autre dans l'Orcus? avec moi déroulez les immenses tableaux de la guerre.»

Les intertextes utilisés par Virgile, vraisemblablement enniens pour le passage concerné d'après Servius $(A .9,526)$, ne doivent pas masquer le jeu sur l'identité de l'allocutaire. L'ambiguïté soulignée par le passage du pluriel (uos/aspirate) au singulier (o Calliope), relevée dans le commentaire servien par la mention d'une syllepse sur le nombre ${ }^{78}$, revient à la question du choix de la Muse invoquée, comme pour le proème à Érato: est-ce véritablement Calliope pour elle-même, ou bien en tant que Muse particulière pour signifier tout le groupe, que le poète a convoquée à cet endroit de son poème?

Il est probable que les deux possibilités aient été envisagées par le poète et intégrées à son poème, et ce jeu littéraire est peut-être lui-même un trait d'érudition alexandrine. On retrouve en effet cette alternative entre singulier et pluriel chez un certain Rhianus $\mathrm{du}$ III ${ }^{\mathrm{e}}$ siècle av. J.-C., cité dans une scholie à Apollonios de Rhodes (Scholia uetera In Apollonium Rhodium ad 3, 1-5) ${ }^{79}$ :

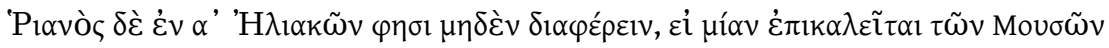

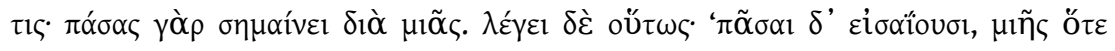

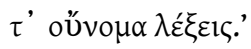

«Rhianos, dans le premier livre des Héliaques, dit qu'il n'y a aucune différence lorsqu'on appelle une Muse pour n'importe laquelle d'entre elles; car on signifie toutes les muses à travers une seule. Il dit en effet ceci : "Toutes entendent, lorsque tu prononces le nom d'une seule." " 
Ainsi, en juxtaposant de façon elliptique une apostrophe au pluriel uos $(9,525)$ et la mention spécifique de Calliope, le poète, sans doute conscient par ailleurs de cette tradition rappelée par le scholiaste, semble traduire un double rattachement et placer son poème sous un double patronage : celui des muses en général et de Calliope en particulier. Il n'est pas difficile de justifier la présence de Calliope dans un poème épique ${ }^{80}$; les seules bella mentionnées au vers 528 légitiment le recours à la muse de la poésie héroïque. Le fragment 7, 22-24 (éd. Pfeiffer) des Aitia de Callimaque justifie par ailleurs une approche spécifiquement mémorielle de cette invocation à Calliope puisque le poète hellénistique débute l'un de ses poèmes étiologiques en mentionnant précisément Calliope :

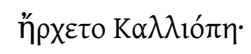

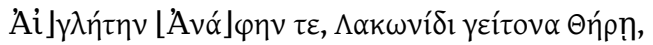

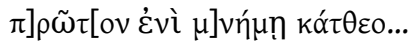

«Calliope commença: Mets en ta mémoire le dieu resplendissant et Anaphé, la

voisine de Théra la Laconienne...»

Cette référence permet de montrer que, comme pour l'ensemble des passages virgiliens qui offrent une invocation à la Muse $(1,8)$ ou aux déesses de l'Hélicon $(7,641)$, le rapport avec la mémoire n'est jamais très loin. Si la présence d'Érato en revanche est beaucoup plus délicate à justifier du point de vue herméneutique, lors de son invocation aussi le poète fait appel aux capacités mémorielles de la Muse $(7,41$ : mone; ainsi que le préfixe re-contenu dans le verbe reuocabo en 7,40 , qui implique un retour des événements dans la mémoire du poète). L'intertexte apollonien des Argonautiques $(3,1)$ explicitait déjà ce rapport établi entre la Muse et la mémoire, que la réception tardive du proème de l'épopée d'Apollonios par le sophiste Athénée (Deipnosophistae 13, 1, 8-16) rend plus saillant encore ${ }^{81}$. Reste à savoir pourquoi Érato? Elles ne sont que deux Muses, Érato et Calliope, à être citées nommément par le poète de l'Énéide.

61 Érato semble jouer à contre-emploi, d'autant que ce sont des rois $(7,37:$ reges $)$, une flotte $(7,38$ : classem), des armées $(7,39$ : exercitus) et le début des combats $(7,40$ : exordia pugnae) dont le poète demande à se souvenir par son intermédiaire, et non, comme on pourrait s'y attendre du fait même de la fonction de cette muse ${ }^{82}$, des histoires d'amour. La critique virgilienne semble aujourd'hui aller vers une interprétation fondée sur le rapprochement étymologique Érato/غ̇ $\rho \omega \tau \omega^{\alpha} \omega^{83}$, qui soulignerait, dans cet emploi virgilien du nom de la Muse, une combinaison herméneutique alliant l'invocation traditionnelle proémiale homérique à la fonction programmatique des invocations hellénistiques ainsi que la poétique apollonienne des Argonautiques à la technique étiologique callimachéenne (à travers un probable renvoi au frg. 238, 8 de Callimaque ${ }^{84}$ ). Si nous ne nions en rien la très probable présence de l'ensemble de ces références en creux de l'extrait virgilien, nous préférons cependant partir de l'hypothèse conforme à l'étymologie traditionnelle du nom d'Érato rappelée par Apollonios de Rhodes ${ }^{85}$ et à la connotation érotique qu'il comporte, comme l'a parfaitement démontré $\mathrm{D}$. Nelis ${ }^{86}$. Parce qu'elle renvoie à tout un arrière-plan érotique et amoureux, Érato, alliée de surcroît aux considérations mnémoniques évoquées précédemment, pourrait en réalité renvoyer à l'intervention d'une mémoire érotique et de motifs élégiaques au cœur même de l'Énéide. Ainsi, le proème au livre 7 de l'épopée virgilienne correspondrait au bilan poétique tiré par Virgile sur l'intrusion d'une forme différente de la mémoire épique, elle-même représentée par Calliope invoquée au livre 9. En tant que "Muse des amours virgiliennes ", Érato occupe bel et bien une place légitime dans ce proème, "pas tout à fait au milieu ${ }^{87}$ » : Muse qui a présidé aux amours 
de Didon et Énée au livre 4, c'est aussi elle qui se cache en quelque sorte derrière le mariage à venir de Lavinia et Énée ${ }^{88}$, lequel est la cause originelle des combats qui occupent la seconde moitié du poème.

En d'autres termes, l'invocation à Érato $(7,37-41)$ serait une allusion au mode mineur élégiaque que le poète introduit au cœur du mode majeur épique, lequel serait représenté par la prière à Calliope $(9,525-528)$. Chacune des deux Muses est en quelque sorte responsable d'une facette particulière de l'épopée. Il convient donc de considérer les invocations dans l'Énéide à la fois comme impliquant véritablement et pour ainsi dire "en personne" Érato et Calliope pour les compétences poétiques respectives dont elles disposent par ailleurs, mais aussi de façon générique comme des Muses, toutes filles de Mnémosyne et qu'un seul esprit anime selon Hésiode (Th. 60 : Ỏ le nom vaut pro qualicumque musa. Le commentaire de Tibérius Donat à propos de l'invocation à Calliope semble de nature à apporter une conclusion temporaire à cette analyse (Interpretationes uergilianae ad Aen. 9, 525):

uelut unam specialiter Musam et tangens generaliter sub plurali numero uniuersas, ut omnes rogatae uideantur

«spécifiquement, comme si le poète convoquait une seule Muse, et de façon générale il touche aussi toutes les muses, grâce au pluriel, puisqu'il semble faire sa demande à toutes ».

\section{Une Voix de Mémoire diffractée}

63 De façon explicite (memora, mone...) ou bien de façon indirecte, par le jeu des intertextes, le poète lie systématiquement la présence des Muses à l'activité mémorielle et aux souvenirs d'origine divine auxquels lui-même subordonne la création du poème épique. La prise en compte de l'ensemble de ces phénomènes énonciatifs envisagés selon une approche métalittéraire témoigne de ce que les Muses virgiliennes pourraient n'être pas tant des Muses véritables qu'une allégorie aux multiples visages incarnant l'activité mémorielle. Car s'il est vrai qu'Érato et Calliope ont des traits caractéristiques bien déterminés, leur filiation avec la Mnémosyne grecque et surtout la constance avec laquelle le poète lie systématiquement les déesses de l'Hélicon avec le travail de mémoire laissent penser que toutes ces Muses (Muse ordinaire ou Muse spécifique, Muse au singulier ou Muses au pluriel) ne sont en réalité que des masques qui reflètent la diffraction de cette Voix de Mémoire portée par une divinité que Virgile dépeint très clairement comme protéiforme.

Cette hypothèse de l'éclatement de la Voix de Mémoire dans l'Énéide pourrait également légitimer le vers 646 du livre 7 :

ad nos uix tenuis famae perlabitur aura

"c'est un faible bruit de ces actions renommées qui parvient avec peine à nos oreilles ».

D'abord, parce qu'elle couvre un domaine allant de la mémoire élégiaque à la mémoire épique et parce qu'elle repousse sans cesse les limites génériques, cette incarnation de l'activité mémorielle ne saurait avoir de dénomination propre dans le récit virgilien; son nom varie au même titre que bougent les frontières de la mémoire convoquée par le poème épique, au même titre encore que changent les spécificités requises par le poète qui s'adresse tantôt à une Muse tantôt à l'autre. En second lieu, la raison pour laquelle le poète ne perçoit qu'une infime partie (tenuis aura) de tout ce qu'il s'apprête à dire et à chanter dans son poème est peut-être tout simplement le fait que la diffraction 
de la Voix de Mémoire empêche la pleine et totale perception par le poète de ce que l'activité mémorielle est susceptible de lui donner à entendre, exactement de la même façon qu'il existe, dans le processus même de l'exercice de la mémoire artificielle, une déperdition d'informations. La Voix de Mémoire possède ainsi des souvenirs entiers (meministis) et elle est capable de les insuffler (memorare potestis), mais ceux-ci ont sans doute perdu de leur force dans le passage de la divinité au poète. Il est donc plausible, étant donnée en outre la variété dans la convocation des Muses qui n'interdit pas de penser que d'autres Muses encore se cachent derrière les traits des déesses de l'Hélicon ${ }^{89}$, que le poète avoue ici l'ouverture possible à d'autres types de mémoire dont lui-même ne se rappelle pas explicitement mais auxquels il ne ferme pas les portes de son œuvre. Parce qu'il n'est qu'un uates humain récipiendaire d'un savoir mémoriel divin, le poète ne peut être assuré de capter l'intégralité des souvenirs que la Voix de Mémoire accepte de lui céder. D'où ce «bruit léger » qu'il perçoit et qui témoigne de la conscience que le poète a de ne pas être capable de restituer fidèlement les propos dispensés par la Voix de Mémoire ${ }^{90}$.

\section{Conclusion}

L'absence de déesse de la Mémoire à Rome a donc peut-être conduit Virgile à remplacer une divinité inexistante par une figure protéiforme empruntant tantôt les traits d'une Muse indécise, tantôt l'identité de l'ensemble des déesses de l'Hélicon, tantôt la voix d'Érato ou celle de Calliope, auxquelles le poète recourt pour solliciter leur mémoire bienveillante. Cette Voix diffractée, écho de l'activité mémorielle qui semble résonner dans l'Énéide, revêt le masque d'une Muse conforme à la tradition poétique antérieure. Elle donne vie à l'épopée, elle lui donne sa fonction, elle en donne une puissante clef exégétique : à tous les sens du terme, l'Énéide est une œuvre de mémoire.

\section{BIBLIOGRAPHIE}

Pour les éditions des textes anciens, nous avons majoritairement utilisé les textes donnés par les CD-Rom du TLL et du TLG. Nous renvoyons donc le lecteur aux éditions de référence de ces deux bases de textes.

\section{Textes anciens}

Ennianae poesis reliquiae, iteratis curis recensuit J. vAHLEN, Amsterdam, A. M. Hakkert, 1967

[reproduction en fac-sim. de l'éd. de Leipzig, Teubner, 1928].

Virgile, Énéide, Livres I-IV, texte établi et trad. par J. PERRET, $2^{\mathrm{e}}$ éd. du 4 e tirage revu et corr. par R. LESUEUR, CUF, Paris, Les Belles Lettres, 1999.

Virgile, Énéide, Livres V-VIII, texte établi et trad. par J. PERRET, $7^{\mathrm{e}}$ tirage, CUF, Les Belles Lettres, Paris, 2002. 
Virgile, Énéide, Livres IX-XII, texte établi et trad. par J. PERRET, $3^{\mathrm{e}}$ tirage, CUF, Les Belles Lettres, Paris, 2002.

Seruii grammatici qui feruntur in Vergilii carmina commentarii, recensuerunt G. THILO et H. HAGEN. I, Aeneidos librorum I-V commentarii ; II, Aeneidos librorum VI-XII commentarii, Hildesheim, G. Olms, 1961.

Tiberi Claudi Donati ad Tiberium Claudium Maximum Donatianum filium suum interpretationes Vergilianae, primum ad vetustissimorum codicum fidem recognitas edidit H. GEORGII, Leipzig, B. G. Teubner, 1905-1906, 2 vol.

\section{Études modernes}

AUSTIN R. G. 1968, «Ille ego qui quondam... », CQ 18, 1, p. 107-115.

BAHKTINE M. 1978, « Récit épique et roman (méthodologie de l'analyse du roman) », in Esthétique et théorie du roman, Bibliothèque des idées 103, Paris, Gallimard, p. 439-474 [1 $1^{\text {re }}$ éd. : 1941].

BING P. 2008, The Well-Read Muse. Present and Past in Callimachus and the Hellenistic Poets, rev. ed., Ann Arbor, Michigan Classical Press.

CALAME C. 1996, « Montagne des Muses et Mouséia : la consécration des Travaux et l'héroïsation d'Hésiode », in A. HURST, A. SCHACHTER (éd.), La montagne des Muses, Recherches et rencontres 7, Genève, Droz, p. 43-56.

-2000 , Le récit en Grèce ancienne, L’Antiquité au présent, Paris, Belin.

- 2005, Masques d'autorité. Fiction et pragmatique dans la poétique grecque antique, L’Âne d'or 24, Paris, Les Belles Lettres.

CALAME C., CHARTIER R. (éd.) 2004, Identités d'auteur dans l'Antiquité et la tradition européenne, Coll. Horos, Grenoble, J. Millon.

CHAMPEAUX J. 1987, Fortuna. Recherches sur le culte de la fortune à Rome et dans le monde romain des origines à la mort de César. II, Les transformations de Fortuna sous la République, Coll. de l'École française de Rome 64, Rome, École française de Rome.

CLÉMENT-TARANTINO S. 2006, Fama ou la renommée du genre. Recherches sur la représentation de la tradition dans l'Énéide, Thèse de doctorat, Littérature latine, Lille 3.

- 2008, « Amours virgiliennes. L'invocation à Érato (Énéide 7, 37)», in J.-M. FONTANIER (dir.), Amor Romanus = Amours romaines. Études et anthologie, Interférences, Rennes, Presses universitaires de Rennes, p. 27-44.

- 2014, «Je et les autres. Réflexions sur la voix épique dans l'Énéide », in A. ESTÈVES, J. MEYERS (éd.), Tradition et innovation dans l'épopée latine, de l'Antiquité au Moyen Âge, Scripta Receptoria 1, Bordeaux, Ausonius, p. 17-28.

COMMAgER S. 1962, The Odes of Horace. A Critical Study, New Haven, Yale University Press.

DEREMETZ A. 1995, Le miroir des Muses. Poétiques de la réflexivité à Rome, Racines \& Modèles, Villeneuve-d'Ascq, Presses universitaires du Septentrion.

- 2004, « Tradition, vraisemblance et autorité fictionnelle », Dictynna 1 [en ligne]. URL : http:// dictynna.revues.org/159. 
DOMINIK W. J. 1993, « From Greece to Rome: Ennius’ Annales », in A. J. BOYLE (ed.), Roman Epic, Londres, Routledge, p. 37-58.

FEENEY D. 1991, The Gods in Epic. Poets and Critics of the Classical Tradition, Oxford, Clarendon Press. FLORES E. 1998, La Camena, l'Epos e la storia. Studi sulla cultura latina arcaica, Forme materiali e ideologie del mondo antico 32, Naples, Liguori.

FRANCHET D'ESPÈREY S. 2006, « Le proème de l'Énéide comme seuil », REA 108, 2, p. 493-515.

- 2008, «Commencer le texte / commencer l'histoire : récit et performance dans l'Énéide », in B. BUREAU, C. NICOLAS (éd.), Commencer et finir. Débuts et fins dans les littératures grecque, latine et néolatine, Actes du colloque organisé les 29 et 30 sept. 2006 par l'Université Jean Moulin-Lyon 3 et l'ENS-LSH, Coll. du Centre d'études romaines et gallo-romaines 31, Lyon, Université Jean MoulinLyon 3 - CERGR, p. 97-109.

GONZALEZ J. 2000, « Musai Hypophetores: Apollonius of Rhodes on Inspiration and Interpretation », HSPh 100, p. 268-292.

HARDIE A. 2007, «Juno, Hercules, and the Muses at Rome », AJPh 128, p. 551-592.

HÄUSSLER R. 1973, « Der Tod der Musen », A\&A 19, p. 117-145.

HUNTER R. 1993, The Argonautica of Apollonius. Literary Studies, Cambridge, Cambridge University Press.

KYRIAKIDIS S. 1998, Narrative Structure and Poetics in the Aeneid. The Frame of Book 6, Le Rane 23, Bari, Levante Ed.

MALTBY R. 1991, A Lexicon of Ancient Latin Etymologies, Arca 25, Leeds, F. Cairns.

NELIS D. 2001, Vergil's Aeneid and the Argonautica of Apollonius Rhodius, Arca 39, Leeds, F. Cairns.

NOTOPOULOS J. 1938, « Mnemosyne in Oral Literature », TAPhA 69, p. 465-493.

O'HARA J. 2001, « Callimachean Influence on Vergilian Etymological Wordplay », CJ 96, 4,

p. $369-400$.

PASCHALIS M. 1997, Virgil's Aeneid. Semantic Relations and proper Name, Oxford, Oxford University Press.

PIERRE M. 2005, « Rome dans la balance. La poésie augustéenne imite-t-elle la poésie grecque ? », in F. DUPONT, E. VALETTE-CAGNAC (dir.), Façons de parler Grec à Rome, L'Antiquité au présent, Paris, Belin, p. 229-254.

RAYMOND E. 2011, Forsan et haec meminisse iuuabit. Recherches sur les formes et aspects de la mémoire dans l'Énéide de Virgile, Thèse de doctorat, Lettres et civilisations antiques, Lyon 3.

ROSSI L. E. 1968, « La fine alessandrina dell'Odissea e lo ZH $\Lambda$ O $\Sigma$ OMHPIKO $\Sigma$ di Apollonio Rodio », RFIC 96, p. 151-163.

SPENTZOU E. 2002, « Stealing Apollo's Lyre: Muses and Poetic $\tilde{\alpha} \theta \lambda \alpha$ in Apollonius' Argonautica 3 », in E. SPENTZOU, D. FOWLER (ed.), Cultivating the Muses. Struggles for Power and Inspiration in Classical Literature, Oxford, Oxford University Press, p. 93-116.

VERNANT J.-P. 1996, Mythe et pensée chez les grecs. Études de psychologie historique, La Découvertepoche. Sciences humaines et sociales 13, Paris, La Découverte. 


\section{NOTES}

1. Voir l'illustration de Virgilii Maronis priores sex Aenidos, J.L. de La Cerda (dess.), Leonardus Gaultier (grav.). Le frontispice représente les figures des muses Clio et Calliope, Énée portant son père Anchise, l'empereur Octave Auguste ainsi que Virgile. Paris, BNF, Cote : Yc 30/Microfilm R 122316 [en ligne]. URL : http://gallica.bnf.fr/ark:/ 12148/btv1b2200150k.

2. Voir le frontispice des CEuvres complètes de Virgile, publiées à Strasbourg en 1502 par Jean Grüninger. Le dessin original des gravures est de Sébastien Brant. Paris, BNF [en ligne]. URL : http://utpictura18.univ-tlse2.fr/GenerateurNotice.php?numnotice=A7454.

3. C'est le sens de la glose de Servius, A. 1, 8.

4. Pour un examen du proème comme seuil, entre rupture et continuité, et plus particulièrement une étude des v. 8-11, nous renvoyons à FRANCHET D'ESPÈREY 2006, p. 504-505. Voir aussi HARDIE 2007, p. 571-576, qui met d'emblée en résonance le memora initial avec la colère tenace de Junon (memorem ob iram du v. 4), pointant du doigt l'importance de la thématique de la mémoire dès les premiers vers de l'Énéide.

5. Sauf mention contraire, les traductions sont personnelles.

6. VERNANT 1996, p. 110.

7. Sur ce sujet, voir CHAMPEAUX 1987.

8. Nous utilisons le terme de "personnification " pour évoquer la représentation par Virgile d'un inanimé (la mémoire) comme un animé. Le terme d' allégorie ", dans la définition qu'en donne Quintilien (Inst. 9, 2, 46) comme d'une «métaphore continuée ", était également séduisant mais le complément de la notice qui souligne une forme d'altérité entre le mot et le sens (Quintilien, Inst. 8, 6, 44: allegoria... aliud uerbis, aliud sensu ostendit) pose problème dans notre optique. Sur les différences terminologiques entre personnification et allégorie, nous renvoyons à l'excellente synthèse de CLÉMENTTARANTINO 2006, p. 82, n. 1.

9. Un certain nombre de ces références figure dans l'énumération des enfants de la Nuit dans la Théogonie, v. 223-232.

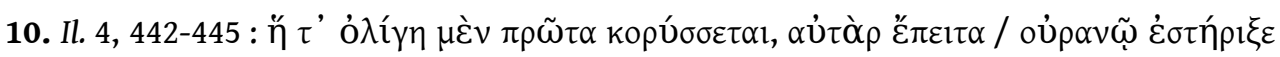

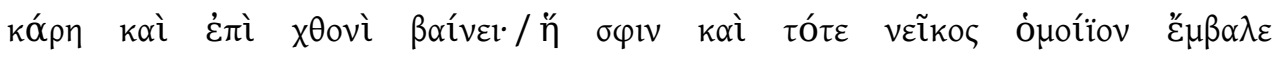

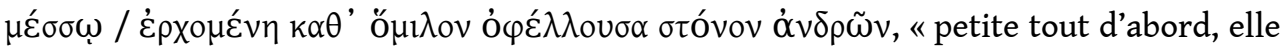
se redresse soudainement, puis tout à coup sa tête touche le ciel tandis qu'elle continue à marcher sur le sol; c'est elle-même qui, encore une fois, vient jeter le trouble au milieu des esprits assemblés et fait s'enfler les gémissements des humains ».

11. FEENEY 1991, p. 242.

12. Voir ClÉMENT-TARANTINO 2006, p. 82 sq.

13. La déesse est chantée dans la Théogonie v. 54, 135 et 915.

14. Hésiode, Th. 32 et 38.

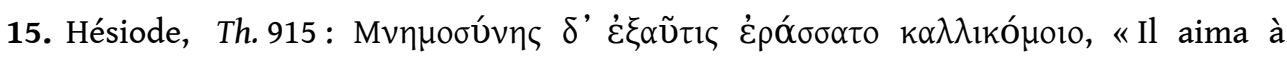
nouveau Mnémosyne à la belle chevelure ».

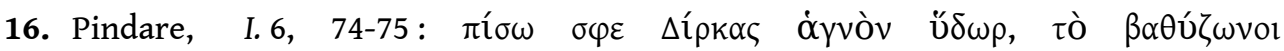

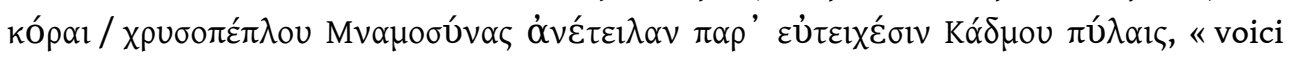


ceux que j'abreuve à la fontaine de Dircé, que les filles à la large ceinture de Mnémosyne au péplos d'or firent jaillir devant les portes de la cité de Cadmos ».

17. NOTOPOULOS 1938, p. 474.

18. Voir CALAME 2000, p. 104-105.

19. Nous empruntons cette expression à HÄUSSLER 1973.

20. Sur ce jeu énonciatif chez Hésiode, voir CALAME, CHARTIER 2004, p. 18 sq.

21. CALAME 2000, p. 109.

22. CALAME, CHARTIER 2004, p. 22.

23. J. Gonzalez (2000) estime qu'Apollon est placé dans le proème en vertu de ses deux fonctions : "non seulement Apollon va présider et autoriser la performance du poète mais avec beaucoup d'à-propos il met en place l'intrigue par l'oracle délivré à Pélias ». Si Apollon a remplacé les Muses dans leur fonction de divinités tutélaires et inspiratrices de la performance épique, c'est parce qu'Apollonios veut résolument se démarquer de la tradition homérique. La mention d'Apollon dans le proème programmatique des Argonautiques correspond à l'affirmation par le poète du choix de l'écart par rapport à ses prédécesseurs.

24. Apollonios commence son chant en révélant la prophétie émise par Apollon et dont avait entendu parler Pélias qui annonçait la venue du héros Jason.

25. Apollonios de Rhodes, Argonautiques 1, 22: «Que les Muses soient les guides de ce chant. »

26. Sur l'ensemble de la question, voir la synthèse de GONZALEZ 2000.

27. Cette hypothèse rejoint l'écho textuel repéré par Rossi 1968, p. 161, n. 4.

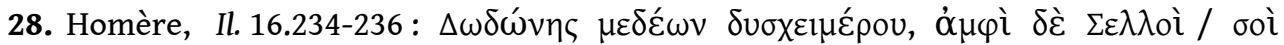

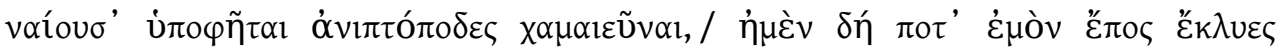

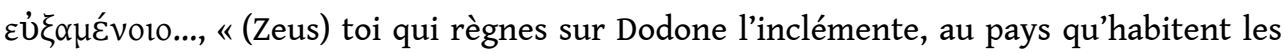
Selles, tes interprètes aux pieds jamais lavés qui couchent sur le sol... »

29. S'il est vrai qu'Apollonios a souhaité mettre à distance l'épopée homérique, on comprend aisément pourquoi l'adjectif u் verbe ن்

30. Voir HUNTER 1993, p. 105.

31. Sur la progressive indépendance des Muses apolloniennes, voir FEENEY 1991, p. $90-93$.

32. Nous « forçons » volontairement la valeur de l'enclitique $\delta$ ' et du verbe $\alpha \dot{\varepsilon} \delta$ $\delta \omega$ pour appuyer notre démonstration.

33. FEENEY 1991, p. 91.

34. Ce dévoiement n'est pas sans rappeler une certaine influence pindarique. La quatrième Pythique (v.1-4) de Pindare s'ouvre sur une préfiguration de l'invocation

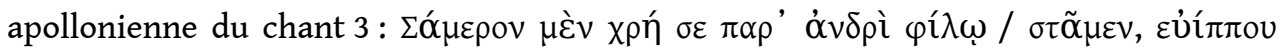

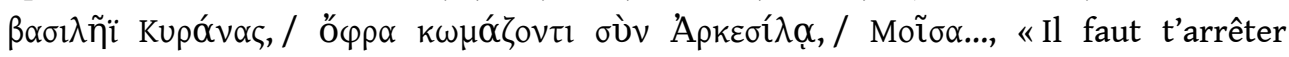
aujourd'hui chez un homme qui m'est cher, chez le roi de Cyrène aux beaux coursiers, afin que pour Arcésilas en fête, Muse... ». La " délocalisation» des Muses, depuis leurs sommets traditionnels jusque vers le monde civil grec, constitue symboliquement un changement de destination qui pourrait métaphoriquement être envisagé comme un élément réflexif augurant du changement de position opéré par Apollonios par rapport 
à la tradition épique. Ainsi, sans pour autant voir une quelconque dépréciation de la poésie alexandrine d'Apollonios dans l'association Homère/Hélicon - Apollonios/terre des hommes, il semble que la "déviation» des Muses puisse représenter, de façon figurée, un « dévoiement » de la poétique des Muses.

35. CALAME 2000, p. 83.

36. Nous empruntons cette expression à SPENTZOU 2002.

37. Voir Ennius, Ann. 15, 1 (éd. vaHLEN, 1967, p. 72).

38. HARDIE 2007, p. 551 et $560 \mathrm{sq}$.

39. Le frg. 2, éd. Vahlen, du livre 1 des Annales d'Ennius pose clairement l'équivalence des Muses et des Camènes: Musas quas memorant, nosce nos esse Camenas; mais le frg. 326, éd. Vahlen, du livre 10, qui débute sur les mots Insece Musa..., définit une option différente qu'Ennius a privilégiée par rapport au vers saturnien de l'Odyssia d'Andronicus (frg. 1, éd. Morel), Virum mihi, Camena, insece uersutum, habituellement considéré comme la stricte transcription latine du v. 1 de l'Odyssée d'Homère. Selon FLORES 1998, p. 51-62, la prédilection d'Ennius pour la musa correspondrait au rétablissement de sa fonction mnémonique, fonction qui ne semble pas dévolue à la Camène d'Andronicus, « équivalent grossier » de la Moṽ $\sigma$ homérique (selon ErnoutMeillet) utilisé par un auteur qui, en sa qualité de traducteur en latin de l'épopée grecque, n'a pas eu besoin d'invoquer la muse de la création. À l'époque de Virgile, l'abandon progressif des Camènes au profit des Muses est sensible dans la poétique horatienne qui oppose à seulement 11 mentions des camènes 26 occurrences évoquant l'activité et/ou la présence de la Muse. Virgile ne fait donc que confirmer cette tendance en opposant aux seules Camènes de l'Églogue 3, 59 quelque 16 mentions de la Muse dans l'ensemble de ses œuvres.

40. Varron, L. 7, 20, assimile l'Olympe au ciel : MVSAE QVAE PEDIBVS MAGNVM PVLSATIS OLYMPVM caelum dicunt Graeci Olympum, montem in Macedonia omnes; a quo potius puto musas dictas Olympiadas: ita enim ab terrestribus locis aliis cognominatae Libethrides, Pipleides, $<T>$ hespiades, <H>eliconides, "MVSAE QVAE PEDIBVS MAGNVM PVLSATIS OLYMPVM: Les Grecs disent que l'olympe est le ciel, tout le monde dit que c'est une montagne en Macédoine; je pense que c'est pour cette raison qu'on appelle plutôt les Muses "olympiennes" : ainsi, de fait, elles tirent leurs surnoms d'autres endroits terrestres: "de Libethra", "de Pimpla", "de Thespies”, "de l'Hélicon” ». Le commentaire varronien sur l'ascension des Muses vers le ciel, par rapport à la représentation prosaïque des Muses apolloniennes, n'implique pas nécessairement un sens moral d'élévation des Muses mais contribue à l'ennoblissement des divinités inspiratrices et à leur rétablissement dans leur dignité. La distinction entre le nom divin et les surnoms terrestres des Muses correspond peut-être chez Varron à une différenciation entre leur essence divine et la projection plus humaine opérée par les poètes notamment.

41. Ennius, Ann., frg. 4-5, éd. Vahlen : somno leni placidoque reuinctus [...] uisus Homerus adesse poeta.

42. Cette interprétation métalittéraire du songe d'Ennius recoupe l'avis de DOMINIK 1993, p. 41.

43. La différence notable entre Ennius (tout à fait homérique) et Virgile (beaucoup plus alexandrin) s'explique bien évidemment par le contexte littéraire de rédaction de chacune de leurs épopées. L'importance de l'alexandrinisme à Rome au début du Principat augustéen constitue un arrière-plan dont il faut tenir compte dans 
l'évaluation de la poétique virgilienne vis-à-vis de son prédécesseur direct dans le genre épique.

44. Ces vers furent conservés en effet dans la Vie de Virgile (42) par Tibérius Donat ainsi que par Servius (éd. THILO \& HAGEN, 1961, p. 2). Sur l'historique et la congruence de ces quelques vers, voir AUSTIN 1968.

45. Sur l'organisation par étapes du proème virgilien, voir FRANCHET D'ESPÈREY 2008.

46. CALAME 2000, p. 17-48.

47. M. Pierre (2005, p. 242-246) effectue un tour d'horizon rapide de la question et cite les travaux d'A. Deremetz (1995, p.117-128) qui rappelait déjà la notion de primus inuentor qu'il rattachait au mythe romain de la double fondation.

48. DEREMETZ 2004, p. 20.

49. COMMAGER 1962, p. 2-3.

50. Sur la capacité de Virgile à s'approprier plusieurs voix sans jamais les laisser prendre le pas sur la sienne, voir CLÉMENT-TARANTINO 2006, p. 30.

51. Sur la réflexion menée par Virgile dans l'Énéide sur le rôle de la mémoire dans sa poétique, voir RAYMOND 2011.

52. Sur ce passage, voir CLÉMENT-TARANTINO 2014, p. 19-20.

53. Pour une description du Muséion, voir Pausanias 29, 5 - 30, 11. Voir aussi calame 1996, p. 44-45.

54. Voir l'excellent développement de CLÉMENT-TARANTINO 2006, p. 509-512.

55. Le Tabularium était l'endroit où étaient conservées les archives à Rome.

56. Lucrèce, 1, 55: et rerum primordia pandam, «et je te révélerai les principes des choses", et 5, 54: atque omnem rerum naturam pandere dictis, "et de nous révéler l'entière nature des choses ".

57. PASCHALIS 1997, p. 259-260, propose de rapprocher le verbe pandere de son double grec $\dot{\varepsilon} \lambda i ́ \sigma \sigma \omega$ qui signifie « dérouler un papyrus ».

58. L'OLD. (s.u. «pando ») donne en effet les sens (1 et 2) de « to spread out, to open out, to stretch out ».

59. BING 2008, p. 10-48.

60. Servius, A. 7, 641 : MOVETE legitur et monete, « MOVETE : on lit aussi monete ».

61. En L. 6, 49-50, Varron fait le lien entre la mémoire qui reste (manere) et la mémoire qui rappelle (monere); il rattache étymologiquement le verbe monere à la notion de memoria : meminisse a memoria, cum id quod remansit in mente tin id quod rursus mouetur; quae a manendo ut manimoria potest esse dicta. [...] ab eodem monere, quod is qui monet, proinde sit ac memoria; sic monimenta quae in sepulcris, et ideo secundum uiam, quo praetereuntis admoneant et se fuisse et illos esse mortalis. ab eo cetera quae scripta ac facta memoriae causa monimenta dicta, «meminisse vient de memoria, parce que ce qui est resté dans l'esprit est à nouveau mis en mouvement; la mémoire peut venir de manere comme on dit manimoria. Et l'origine en est le même verbe monere, parce que celui qui avertit fait aussi preuve de mémoire ; ainsi on appelle monimenta les choses qui, dans les tombeaux, et de la même façon le long des routes, avertissent les passants qu'ils sont mortels et que ceux qui sont là l'ont été aussi. De là vient que toutes les choses écrites ou faites pour mémoire sont appelées monimenta ». 
62. En A. 1, 8, on notera la place des mots au sein du vers : la Muse (Musa) ouvre le vers, suivie du pronom personnel mihi représentant le poète, qui se trouve au carrefour entre la Muse et le verbe memora qui désigne l'activité mémorielle. De façon quelque peu mimétique, le poète occupe la place de récipiendaire du savoir et de la mémoire des Muses.

63. Voir RAYMOND 2011.

64. On retrouve cette familiarité dans le proème à Érato dans lequel la Muse non seulement « inspire » le poète mais « converse » avec lui (KYRIAKIDIS 1998, p. 173).

65. Nous renvoyons, par ex., à Servius $(A .1,8)$ qui reprend les trois parties topiques d'un proème épique : la propositio, l'inuocatio et la narratio : in tres partes dividunt poetae carmen suum : proponunt invocant narrant, « les poètes répartissent leur poème en trois parties : ils proposent, ils invoquent et ils racontent $»$.

66. CLÉMENT-TARANTINO 2014.

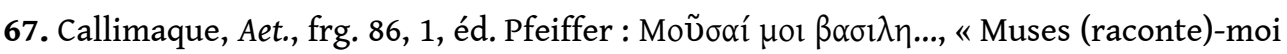
les rois..."

68. L'expression est de C. Calame (2005, p. 137).

69. Il est ici nécessaire de soulever une objection sur le second extrait $(7,641-647)$ qui n'est pas à proprement parler en position proémiale, laquelle est en quelque sorte occupée au livre 7 par l'invocation à Érato, elle-même très légèrement décalée par rapport au début du livre. Cependant, la complémentarité précisément du proème à Érato et de l'invocation ultérieure aux déesses de l'Hélicon en termes de poétique de la mémoire laisse penser que le second extrait est un prolongement du proème "pas tout à fait au milieu» (voir la terminologie de CLÉMENT-TARANTINo 2006, p. 359) qu'est la prière à Érato.

70. Grammaticalement, le pronom nos désigne soit un je + tu soit un je + vous, mais la $1^{\text {re }}$ personne est, dans tous les cas, présente.

71. On peut aussi ajouter le meministis de 7, 645 qui, en tant que parfait à valeur résultative, a un sens présent.

72. Sur ce point, voir RAYMOND 2011.

73. BAKHINE 1978, p. 441-473.

74. Sur ce point, voir l'étude très pertinente de NELIS 2001, p. 267-268 et 274-275, et KYRIAKIDIS 1998, p. 161-164.

75. Nous traduisons volontairement mone par le verbe "remémorer ", en considération des liens qui existent entre le verbe latin et la notion de mémoire. Une recherche détaillée dans le TLL permet de constater que le verbe monere au sens de «se rappeler, se remémorer » est déjà présent dans la littérature latine pré-virgilienne, en particulier dans le théâtre de Plaute. En effet, ce dernier associe très régulièrement le verbe monere avec des termes appartenant au champ lexical de la mémoire. Parmi les exemples les plus significatifs, on retiendra les passages suivants: Capt. 191 et St. 578 : Capti consili memorem mones, "ce sont des conseils inutiles que de me rappeler ce dont je me souviens très bien "; Capt. 240 : et propterea saepius te uti memineris moneo, " et je te le rappelle pour que tu t'en souviennes"; Cas. 998 : monebo, siquidem meministi minus, " je te le remettrai en mémoire si tu ne t'en souviens plus »; Ps. $940:$ memorem immemorem facit qui monet quod memor meminit, «celui qui se souvient perd la mémoire quand on veut lui remettre en mémoire ce dont il se souvient très bien »; Rud. 159 : si non moneas, 
nosmet meminimus, «si tu ne nous le rappelais pas, nous nous en souviendrions tous seuls »; St. 41-42: quam ob rem ego te hoc, soror, tametsi maior, / moneo, ut tuom memineris officium, « ainsi donc, chère sœur, c'est moi qui te rappelle, même si tu es mon aînée, de ne point oublier ton devoir»; St.58-59: qui manet ut moneatur semper seruos homo officium suum / nec uoluntate id facere meminit, seruos is habitu haud probus est, " un esclave qui attend toujours qu'on lui remette en mémoire son devoir, et ne se souvient pas de le faire de lui-même, est un mauvais esclave pour son maître ". Chez Virgile, ce sens du verbe monere paraît pouvoir être applicable à A. 4, 557 : rursusque ita uisa monere est, "l'image du dieu parut lui remettre encore en mémoire... », du fait de l'adverbe itératif rursus impliquant davantage la notion de répétition (et donc celle du souvenir) que celle d'avertissement. D'une manière générale, sur les rapports entre monere et la memoria, nous renvoyons à MALTBY 1991, s.u. « monere » et « memoria ».

76. Concernant le débat, encore vivace, au sujet de l'attribution à chaque Muse, et plus particulièrement à Érato, d'un domaine d'action ou d'une sphère d'activité précise, nous renvoyons à KYRIAKIDIS 1998, p. 162-163 et p. 163, n. 7, et NELIS 2001, p. 268-269, n. 6.

77. CLÉMENT-TARANTINO 2008. Nous renvoyons à KYRIAKIDIS 1998, p. 161, n. 1, et NELIS 2001, p. 268, n. 6 , pour une bibliographie de tous les auteurs ayant pris part à ce débat concernant le proème.

78. Servius, A. 9, 523, développe ainsi : erat enim rectum uos musae aut te, Calliope, "voici ce qui était syntaxiquement juste : "Vous muses, ou bien toi, Calliope" ".

79. Scholia In Apollonium Rhodium uetera 215, 15-18, éd. WENKEL, 1935 [réimpr. 1974]. Le fragment de Rhianus est reproduit isolément dans les Collectanea Alexandrina, frg. 19, éd. POWELL, 1925 [réimpr. 1970].

80. Callimaque, frg. 7, 25, éd. Pfeiffer, rappelle l'adéquation de Calliope avec des sujets

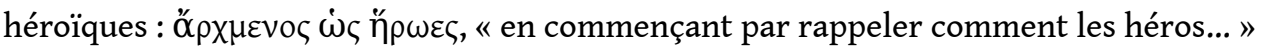

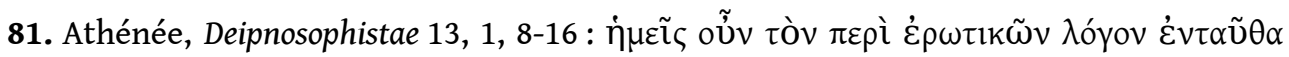

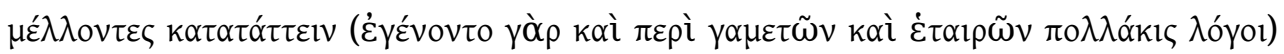

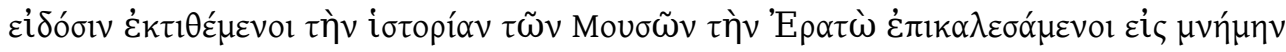

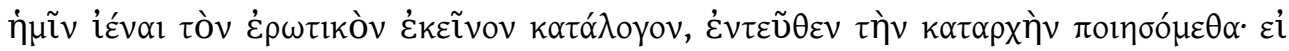

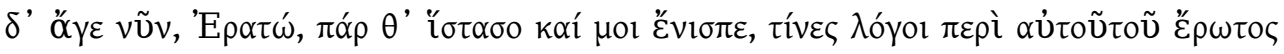

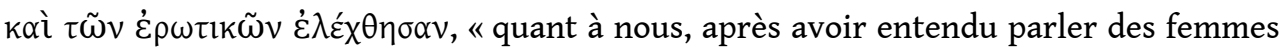
mariées et des courtisanes, nous allons maintenant nous pencher sur des histoires d'amour et les raconter à des gens experts. Mais pour mémoriser ce long catalogue érotique, il nous faut d'abord invoquer la muse Érato; chantons-lui donc ce début: "Viens donc à mes côtés, Érato, et reste auprès de moi puis dis-moi tout ce qui a trait à l'amour et aux affaires du cœur"..."

82. Et aussi de l'intertexte des Argonautiques $(3,1-5)$ où il est question de l'annonce des amours de Médée pour Jason.

83. Sur ce point, voir KYRIAKIDIS 1998, p.161-177; O’HARA 2001, p. 19, et CLÉMENTTARANTINO 2008, p. 28 sq..

84. Callimaque, Fragmenta et titulus, frg. 238, 8, éd. Lloyd-Jones \& Parsons, Supplementum Hellenisticum, Texte und Kommentare 11, Berlin, W. de Gruyter, 1983: 'E $\rho \tau \omega \grave{\omega} \delta$ '

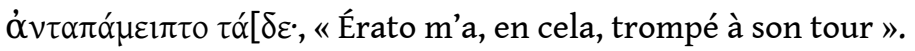




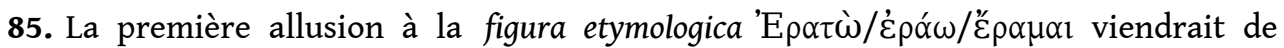

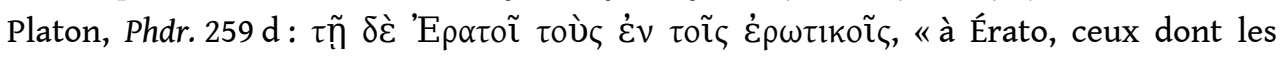
affaires d'amour sont l'occupation ».

86. NELIS 2001, p. 268.

87. La formule est de S. Clément-Tarantino (2006, p. 359).

88. Voir CLÉMENT-TARANTINO 2008, p. 30 sq. L'auteur propose également de considérer Érato comme incarnant l'amour patriotique de Virgile (p. 34-37).

89. Qu'en est-il par ex. de Clio, la Muse de l'histoire? N'est-il pas possible qu'elle fasse partie, même si elle n'est pas nommée, des diuae qui prêtent leurs souvenirs au poète ?

90. S. Kyriakidis (1998, p.166) parle d'une "sérieuse diminution du rôle du poète » à travers l'emphase portée sur les qualités mnémoniques et narratives des Muses, mises en rapport avec les difficultés des mortels et donc du poète à comprendre les événements. L'exaltation du rôle mnémonique des Muses n'implique pas nécessairement l'effacement ni même l'écrasement de la persona poetae. L'analyse du v. 646 qui s'appuie sur le fonctionnement même de la mémoire permet de maintenir l'idée d'un rôle mnémonique capital des Muses tout en ménageant l'importance du uates qui, dans l'Énéide, est loin d'être en retrait.

\section{INDEX}

oeuvrecitee Chants cypriens, Hymnes homériques

Index géographique : Rome

nomsmotscles Africanus (Lucius), Andronicus (Lucius Livius), Apollonios de Rhodes, Arnobe l'Ancien, Athénée, Augustin, Aulu-Gelle, Callimaque, Donatus (Tiberius Claudius), Ennius, Euripide, Hécatée, Hésiode, Homère, Isidore de Séville, Lucrèce, Pindare, Plaute, Quintilien, Rhianus, Servius Honoratus (Maurus), Sophocle, Varron, Virgile

\section{AUTEURS}

\section{EMMANUELLE RAYMOND-DUFOULEUR}

Université d'Angers 